SUPPLEMENTAL INFORMATION

\title{
Discovery of WD Repeat-Containing Protein 5 (WDR5)-MYC inhibitors using fragment-based methods and structure-based design
}

Selena Chacón Simon, ${ }^{a}$ Feng Wang, ${ }^{a}$ Lance R. Thomas, ${ }^{b}$ Jason Phan, ${ }^{a}$ Bin Zhao, ${ }^{a}$ Edward T.

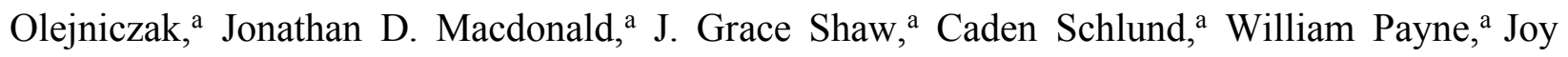
Creighton, ${ }^{\mathrm{b}}$ Shaun R. Stauffer, ${ }^{\mathrm{c}, \mathrm{d}}$ Alex G. Waterson, ${ }^{\mathrm{c}, \mathrm{d}}$ William P. Tansey, ${ }^{\mathrm{b}}$ Stephen W. Fesik. ${ }^{\mathrm{a}, \mathrm{c}, \mathrm{d},{ }^{*}}$

\section{Affiliations:}

a) Department of Biochemistry, b) Department of Cell and Developmental Biology, c) Department of Pharmacology, Vanderbilt University School of Medicine, Nashville, Tennessee, 37232, United States; d) Department of Chemistry, Vanderbilt University, Nashville, Tennessee, 37232, United States

\section{Table of Contents}

Supplemental Data

Supplemental Table 1. NMR-based fragment screening hits.

Supplemental Table 2. Pharmaceutical property profile of select compounds.

Supplemental Table 3. Calculated physicochemical properties of compounds.

Supplemental Table 4. Disruption of the WRAD complex as measured by activity in a commercial HMT.

Supplemental Figure 1. Chemical structure of sulfonamide 30 and the negative control

\section{Chemistry Experimental Details}

Synthesis of negative control compound

HPLC traces for lead compounds 
Supplemental Table 1. Fragment screening hits.

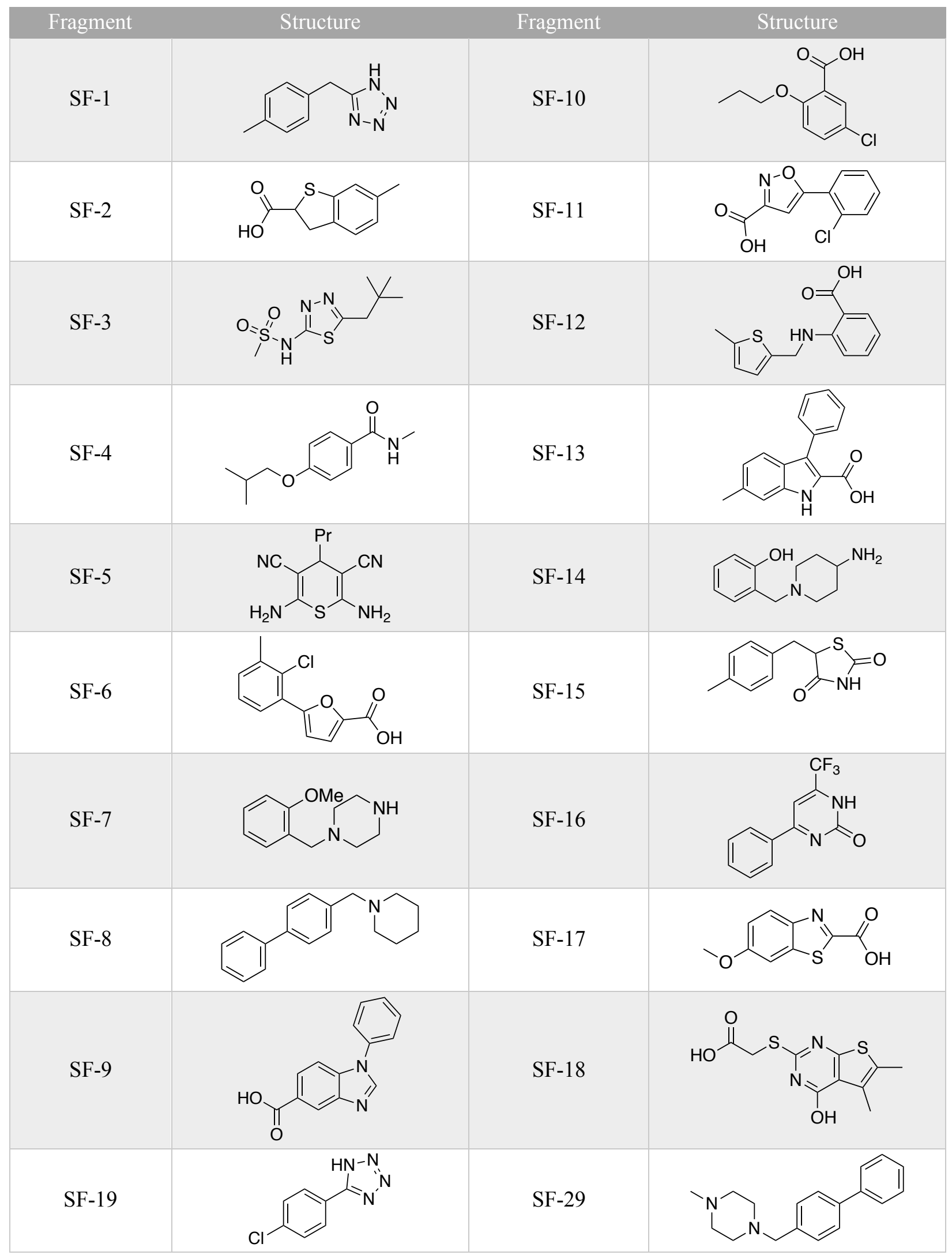




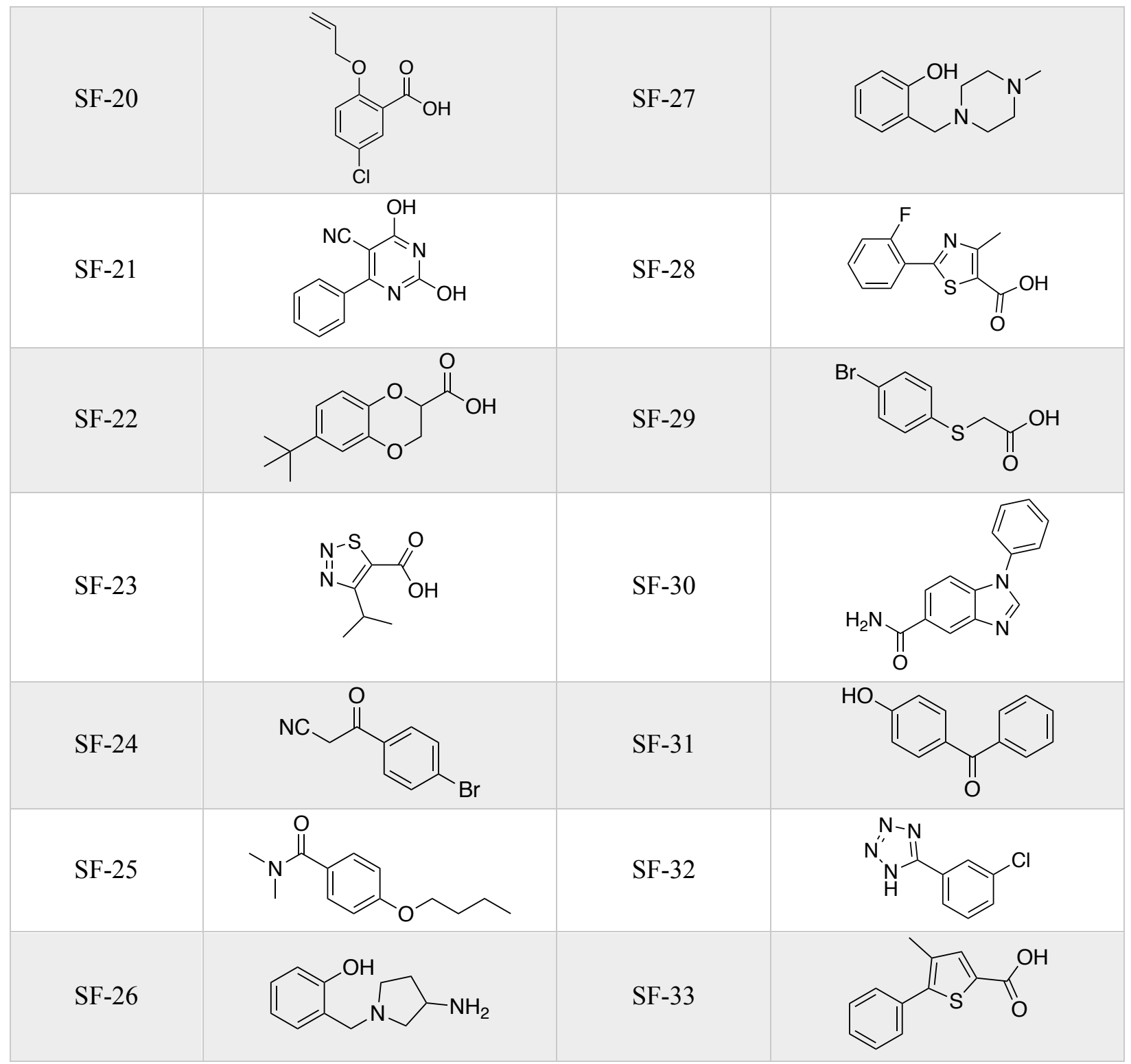

Supplemental Table 2. Pharmaceutical property profile of selected compounds. ${ }^{\mathrm{a}}$

\begin{tabular}{cccc}
\hline Compound & $\begin{array}{c}\text { Solubility } \\
(\boldsymbol{\mu M})\end{array}$ & $\begin{array}{c}\text { MDCK A-B } \\
\mathbf{P}_{\text {app }}(\mathbf{1 0} / \mathbf{s})\end{array}$ & $\boldsymbol{f}_{\mathbf{u}}(\mathbf{\%})$ \\
\hline $\mathbf{3 d}$ & $>100$ & 57.6 & $<0.0005$ \\
$\mathbf{6}$ & $>100$ & 23.9 & $<0.0002$ \\
$\mathbf{8}$ & $>100$ & 23.2 & $<0.0005$ \\
$\mathbf{1 2}$ & $>100$ & 12.0 & $<0.0005$ \\
\hline${ }^{\mathrm{a}}$ All experiments performed at $\mathrm{Q}^{2}$ Solutions Ltd.
\end{tabular}


Supplemental Table 3: Calculated physicochemical properties for different analogs.

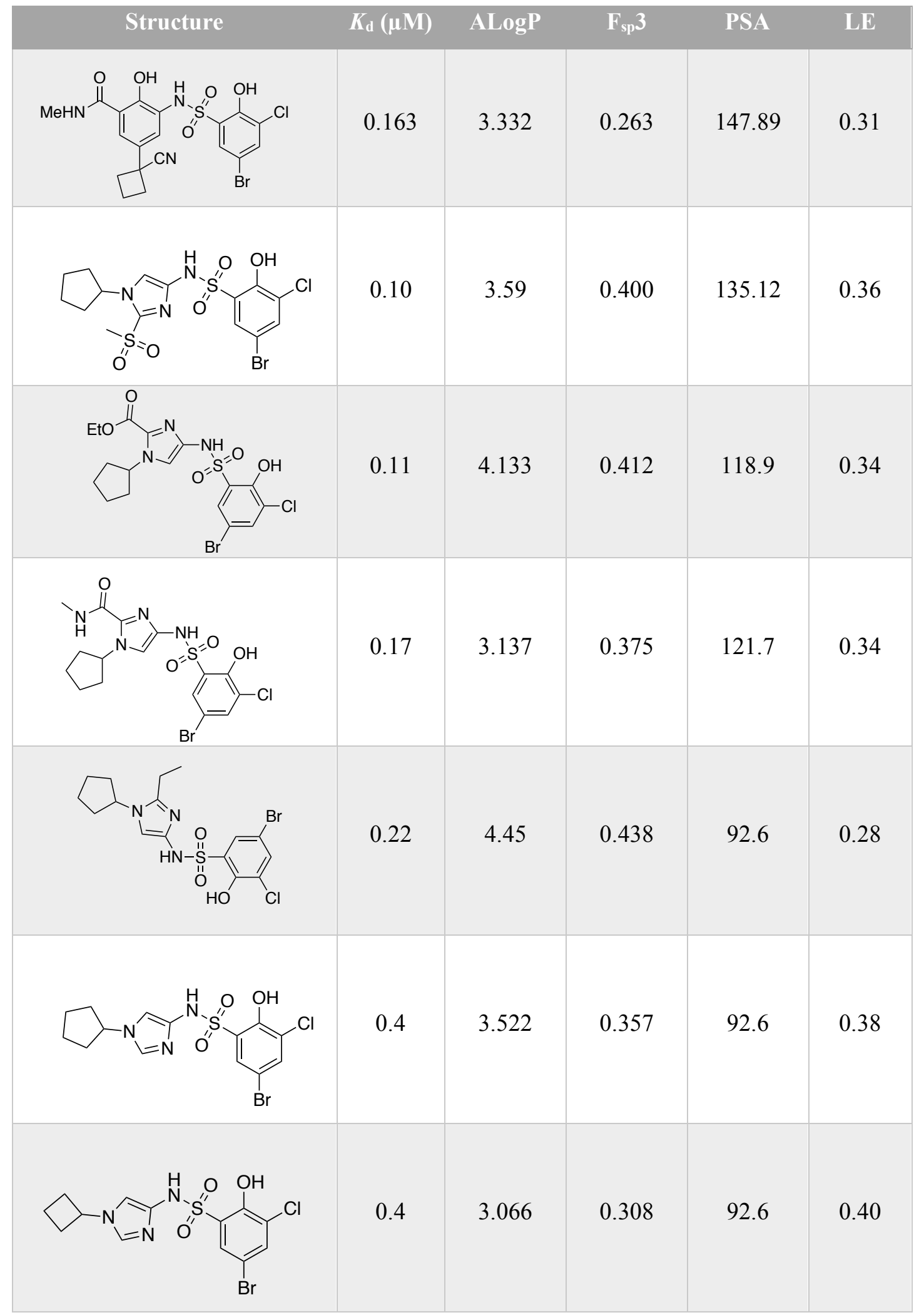




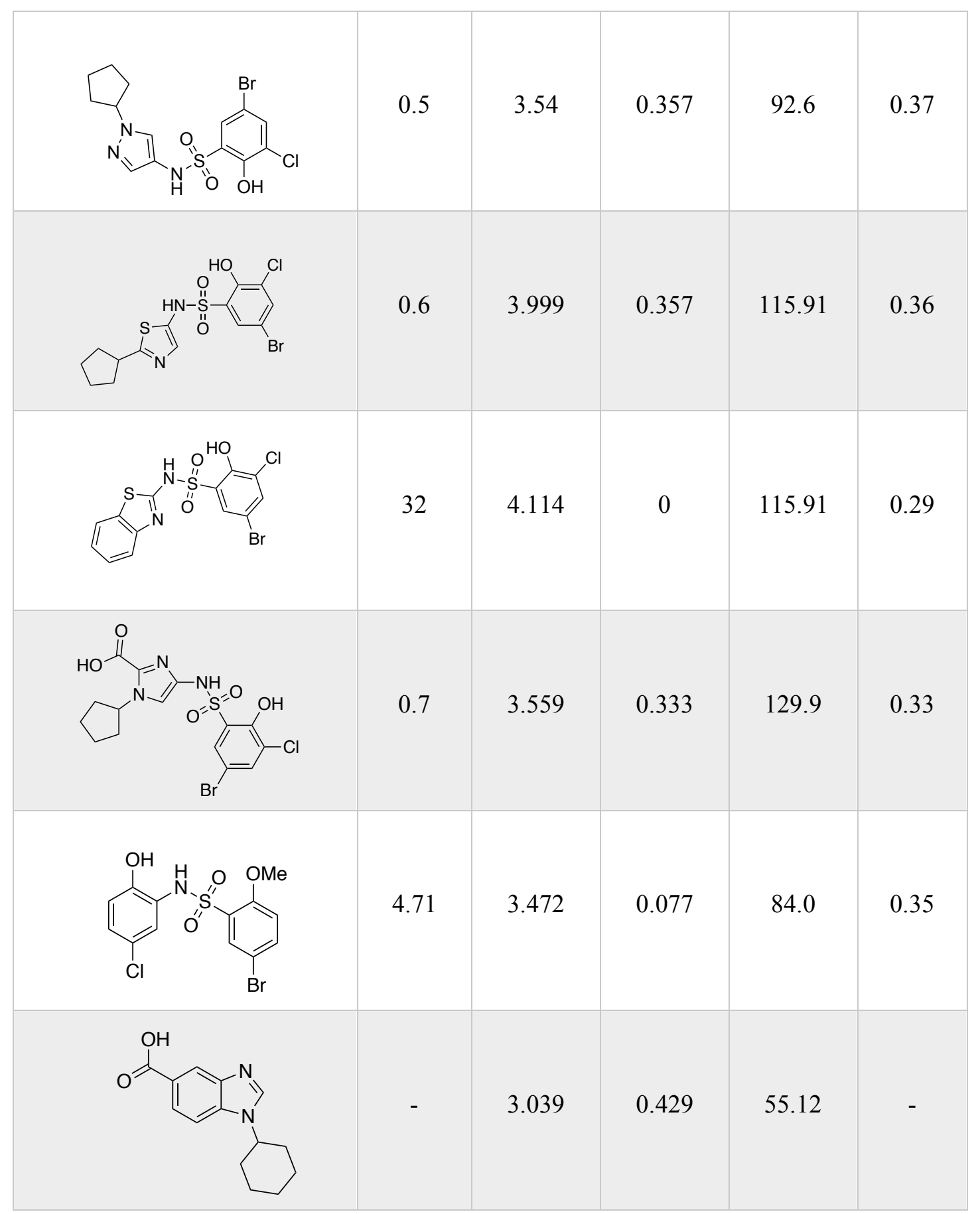


Supplemental Table 4. Disruption of the WRAD complex as measured by activity in a commercial HMT.

\begin{tabular}{ccc} 
Compound & $\begin{array}{c}\text { FPA } \boldsymbol{K}_{\mathbf{d}} \\
(\boldsymbol{\mu M})\end{array}$ & $\begin{array}{c}\text { HMT IC }_{\mathbf{5 0}} \\
(\boldsymbol{\mu M})^{\mathbf{a}}\end{array}$ \\
\hline $\mathbf{3 d}$ & $0.5 \pm 0.1$ & 2.05 \\
$\mathbf{6}$ & $0.11 \pm 0.03$ & 0.581 \\
$\mathbf{8}$ & $0.17 \pm 0.03$ & 1.08 \\
$\mathbf{1 2}$ & $0.10 \pm 0.01$ & 0.404 \\
\hline
\end{tabular}

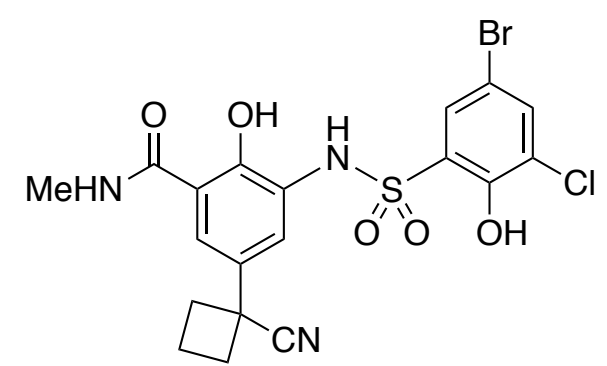

30

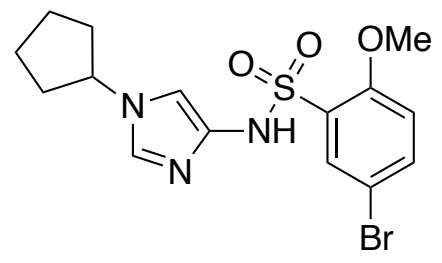

N.C. $\mathrm{K}_{\mathrm{d}}>40 \mu \mathrm{M}$

Supplemental Figure 1. Chemical structure of sulfonamide $\mathbf{3 0}$ and the negative control (N.C.). The $\mathrm{K}_{\mathrm{d}}$ value is representative of three independent replicates. 
A

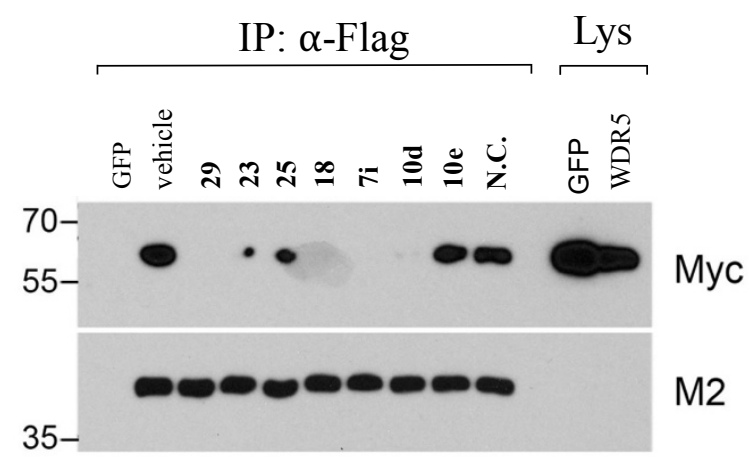

B

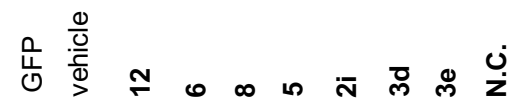

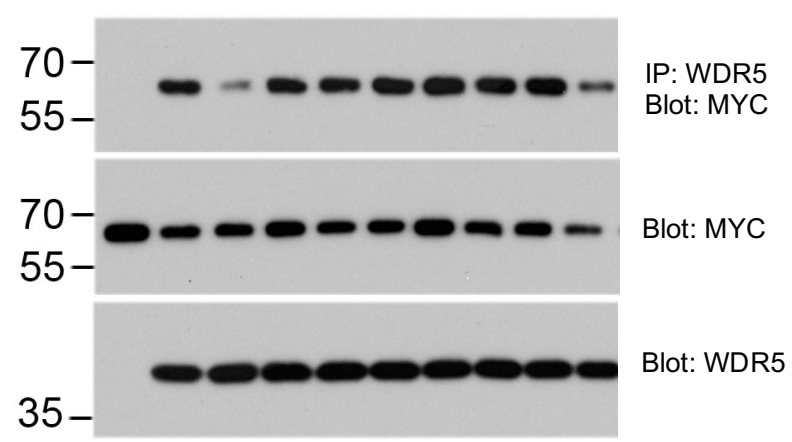

Supplemental Figure 2. Panels A) and B) represent a replication of the blots shown in Figure 8. (A) Compound target engagement in cell lysates. Levels of c-MYC proteins co-precipitating with WDR5 were assessed in cell lysates from WDR5-FLAG and c-MYC-HA co-overexpressing HEK293 cells. A fraction of the lysate before addition of compound is shown as a control lane. Immunoprecipitation with $\alpha$-FLAG was used to isolate WDR5, which is not detectable in the input due to the excess of WDR5 in the immunoprecipitation (IP) fraction. Quantification was performed using ImageJ with the Fiji plugin and normalized to the vehicle control. Data are representative of minimum two independent biological repeats. (B) Compound target engagement in living cells. HEK293 cells were treated for $24 \mathrm{~h}$ with $5 \mu \mathrm{M}$ compound and lysates were prepared and analyzed as in (A). A fraction of the input lysate was blotted to monitor MYC levels in treated cells. 
Supplemental Table 5. X-ray data collection and refinement statistics.

\begin{tabular}{|c|c|c|c|c|c|c|c|c|c|}
\hline Ligand & F-1 & F-5 & F-7 & $2 \mathbf{i}$ & 4 & 8 & 12 & F-2 & F-6 \\
\hline PDB entry & $6 \mathrm{UJJ}$ & 6UJH & $6 U J L$ & 6 UIK & $6 U J 4$ & 6UIF & $6 \mathrm{UOZ}$ & $6 \mathrm{UHY}$ & $6 \mathrm{UHZ}$ \\
\hline No. chains & 1 & 2 & 1 & 2 & 2 & 2 & 2 & 2 & 2 \\
\hline
\end{tabular}

\begin{tabular}{|c|c|c|c|c|c|c|c|c|c|}
\hline $\begin{array}{l}\text { Space } \\
\text { group }\end{array}$ & P212121 & $\mathrm{P} 1$ & P21212 & $\mathrm{C} 2$ & P21 & $\mathrm{P} 1$ & $\mathrm{P} 1$ & $\mathrm{C} 2$ & $\mathrm{C} 2$ \\
\hline \multicolumn{10}{|l|}{$\begin{array}{l}\text { Cell } \\
\text { dimensions }\end{array}$} \\
\hline$a, b, c(\AA)$ & $\begin{array}{l}81.48 \\
86.53 \\
39.75\end{array}$ & $\begin{array}{c}47.13,47.27 \\
68.54\end{array}$ & $\begin{array}{c}81.19,86.12 \\
, 40.71\end{array}$ & $\begin{array}{c}134.26,46.8 \\
8,112.84\end{array}$ & $\begin{array}{c}46.67,96.52,6 \\
4.94\end{array}$ & $\begin{array}{c}46.82,56.84 \\
64.78\end{array}$ & $\begin{array}{c}46.71,56.95 \\
, 64.92\end{array}$ & $\begin{array}{c}134.4646 .95 \\
112.77\end{array}$ & $\begin{array}{c}134.37 \\
46.90 \\
112.46\end{array}$ \\
\hline$\alpha, \beta, y\left({ }^{\circ}\right)$ & $\begin{array}{l}90.00 \\
90.00 \\
90.00\end{array}$ & $\begin{array}{c}89.98,90.50 \\
104.35\end{array}$ & $\begin{array}{c}90.00,90.00 \\
, 90.00\end{array}$ & $\begin{array}{c}90.00,117.3 \\
9,90.00\end{array}$ & $\begin{array}{c}90.00,90.00,9 \\
0.00\end{array}$ & $\begin{array}{c}107.93,91.21 \\
, 114.29\end{array}$ & $\begin{array}{c}108.36,90.7 \\
6,114.17\end{array}$ & $\begin{array}{c}90.00117 .63 \\
90.00\end{array}$ & $\begin{array}{c}90.00 \\
117.61 \\
90.00\end{array}$ \\
\hline $\begin{array}{l}\text { Resolution } \\
(\mathrm{A})\end{array}$ & $38.21-1.73$ & $27.46-1.49$ & $29.58-1.60$ & $28.97-1.60$ & $29.81-1.53$ & $27.51-1.60$ & $27.53-1.53$ & $31.30-1.26$ & $\begin{array}{l}37.28- \\
1.26 \\
\end{array}$ \\
\hline $\begin{array}{l}R_{\text {sym }} / R \text { merg } \\
\text { e }\end{array}$ & $\begin{array}{c}4.50(61.0) / 6 \\
.10(68.0)\end{array}$ & $\begin{array}{c}5.1(23.8) / 5.9 \\
(27.1)\end{array}$ & $\begin{array}{l}5.30(73.9) / \\
6.90(76.8)\end{array}$ & $\begin{array}{l}5.60(22.0) / \\
6.1(20.5)\end{array}$ & $\begin{array}{c}9.0(28.6) / 9.3( \\
26.1)\end{array}$ & $\begin{array}{c}5.9(27.9) / 5.3 \\
(18.5)\end{array}$ & $\begin{array}{c}4.0(27.0) / 4 \\
7(20.8)\end{array}$ & $\begin{array}{c}6.1 \\
(37.4) / 5.3 \\
(33.6)\end{array}$ & $\begin{array}{c}5.2 \\
(24.4) / 4.5 \\
(20.9)\end{array}$ \\
\hline$I / \sigma I$ & $22.88(3.48)$ & $12.46(3.15)$ & $17.43(3.58)$ & $43.02(8.74)$ & $14.07(2.93)$ & $25.05(4.4)$ & $30.96(5.08)$ & $33.4(3.7)$ & $34.7(5.7)$ \\
\hline $\begin{array}{l}\text { Completene } \\
\text { ss (\%) }\end{array}$ & $99.8(99.4)$ & $94.7(87.5)$ & $94.5(97.5)$ & $97.5(95.9)$ & $97.6(92.4)$ & $92.6(86.6)$ & $96.1(91.4)$ & $99.3(97.5)$ & $99.6(99.0)$ \\
\hline $\begin{array}{l}\text { Redundanc } \\
\text { y }\end{array}$ & $7.6(7.5)$ & $2.3(2.1)$ & $7.3(7.4)$ & $6.6(5.9)$ & $3.9(2.8)$ & $2.5(2.2)$ & $3.1(2.5)$ & $4.1(4.1)$ & $4.0(3.9)$ \\
\hline
\end{tabular}

\begin{tabular}{|l|c|c|c|c|c|c|c|c|c|}
\hline \begin{tabular}{|l} 
No. \\
reflection \\
S
\end{tabular} & 29845 & 87682 & 36351 & 80495 & 84510 & 69166 & 82516 & 162176 & 163568 \\
\hline $\begin{array}{l}R_{\text {work }} / \\
\text { Rfree }\end{array}$ & $\begin{array}{c}15.50 / 18.9 \\
0\end{array}$ & $\begin{array}{c}14.60 / 16.8 \\
0\end{array}$ & $\begin{array}{c}16.50 / 18.3 \\
0\end{array}$ & $\begin{array}{c}15.92 / 18.2 \\
5\end{array}$ & $15.43 / 17.75$ & $\begin{array}{c}16.68 / 19.3 \\
7\end{array}$ & $\begin{array}{c}14.25 / 16.9 \\
2\end{array}$ & $15.4 / 18.1$ & $15.2 / 17.6$ \\
\hline $\begin{array}{l}\text { RMS } \\
\text { deviation } \\
\text { s }\end{array}$ & 0.008 & 0.006 & 0.004 & 0.006 & 0.10 & 0.006 & 0.014 & 0.0055 & 0.005 \\
\hline $\begin{array}{c}\text { Bond } \\
\text { lengths } \\
(\boldsymbol{A})\end{array}$ & 1.22 & 0.91 & 0.86 & 1.15 & 0.89 & 1.35 & 0.855 & 0.854 \\
\hline $\begin{array}{c}\text { Bond } \\
\text { angles ( }{ }^{\circ} \text { ) }\end{array}$ & 1.08 & 1 & & & & & & \\
\hline
\end{tabular}




\section{Chemistry Experimental Details}

\section{5-Bromo-N-(1-cyclopentyl-1H-imid azol-4-yl)-2-methoxybenzenesulfonamide (N.C.)}<smiles>COc1ccc(Br)cc1S(=O)(=O)Nc1cn(C2CCCC2)cn1</smiles>

Cyclopentyl-1H-imidazol-4-aminium chloride (80 mg, crude) was reacted 5-bromo-2methoxybenzenesulfonyl chloride following General Procedure 4. After purification, $44 \mathrm{mg}(0.11 \mathrm{mmol})$ of the title compound was obtained. ${ }^{1} \mathrm{H}$ NMR $(400 \mathrm{MHz}$, Chloroform- $d) \delta 7.79(\mathrm{~d}, J=2.7 \mathrm{~Hz}, 1 \mathrm{H}), 7.55$ (s, 1H), 7.45 (dd, $J=8.8,2.7 \mathrm{~Hz}, 1 \mathrm{H}), 6.97-6.91$ (m, 2H), 4.43 (p, $J=6.7 \mathrm{~Hz}, 1 \mathrm{H}), 3.94$ (s, 3H), $2.27-2.17$ $(\mathrm{m}, 2 \mathrm{H}), 1.90-1.71(\mathrm{~m}, 6 \mathrm{H})$. LCMS (Method B) $\mathrm{t}_{\mathrm{R}}=0.823 \mathrm{~min}, \mathrm{~m} / \mathrm{z}=400.0[\mathrm{M}+\mathrm{H}]^{+}$; Purity (AUC) $\geq$ 95\%. 
HPLC trace of compound 2a
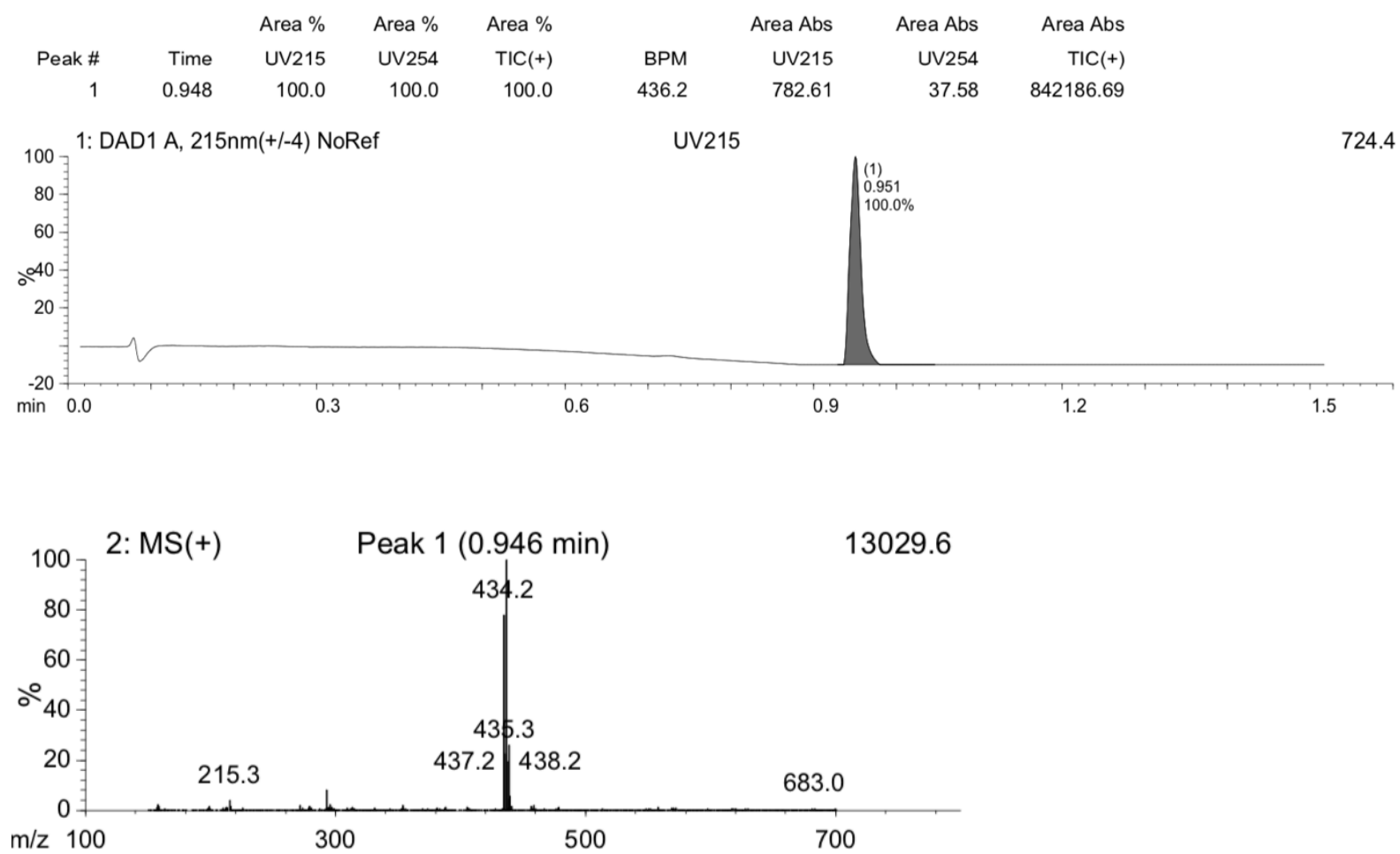

HPLC trace of compound $\mathbf{2 b}$

\begin{tabular}{|c|c|c|c|c|c|c|c|c|}
\hline & & Area \% & Area \% & Area \% & & Area Abs & Area Abs & Area Abs \\
\hline Peak \# & Time & UV215 & UV254 & $\mathrm{TIC}(+)$ & BPM & UV215 & UV254 & $\mathrm{TIC}(+)$ \\
\hline
\end{tabular}

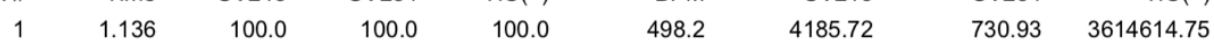
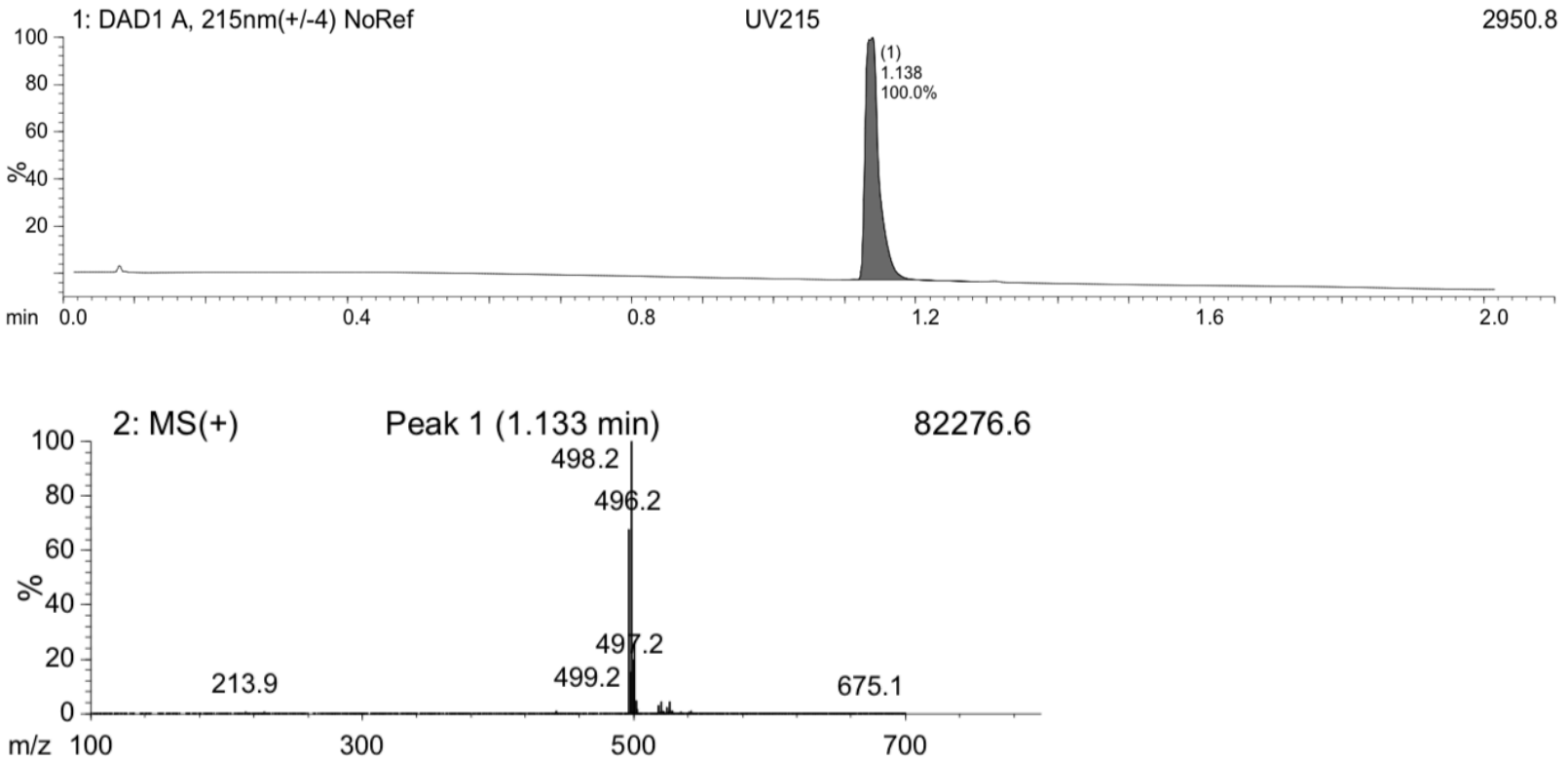
HPLC trace of compound 2c

65318.D

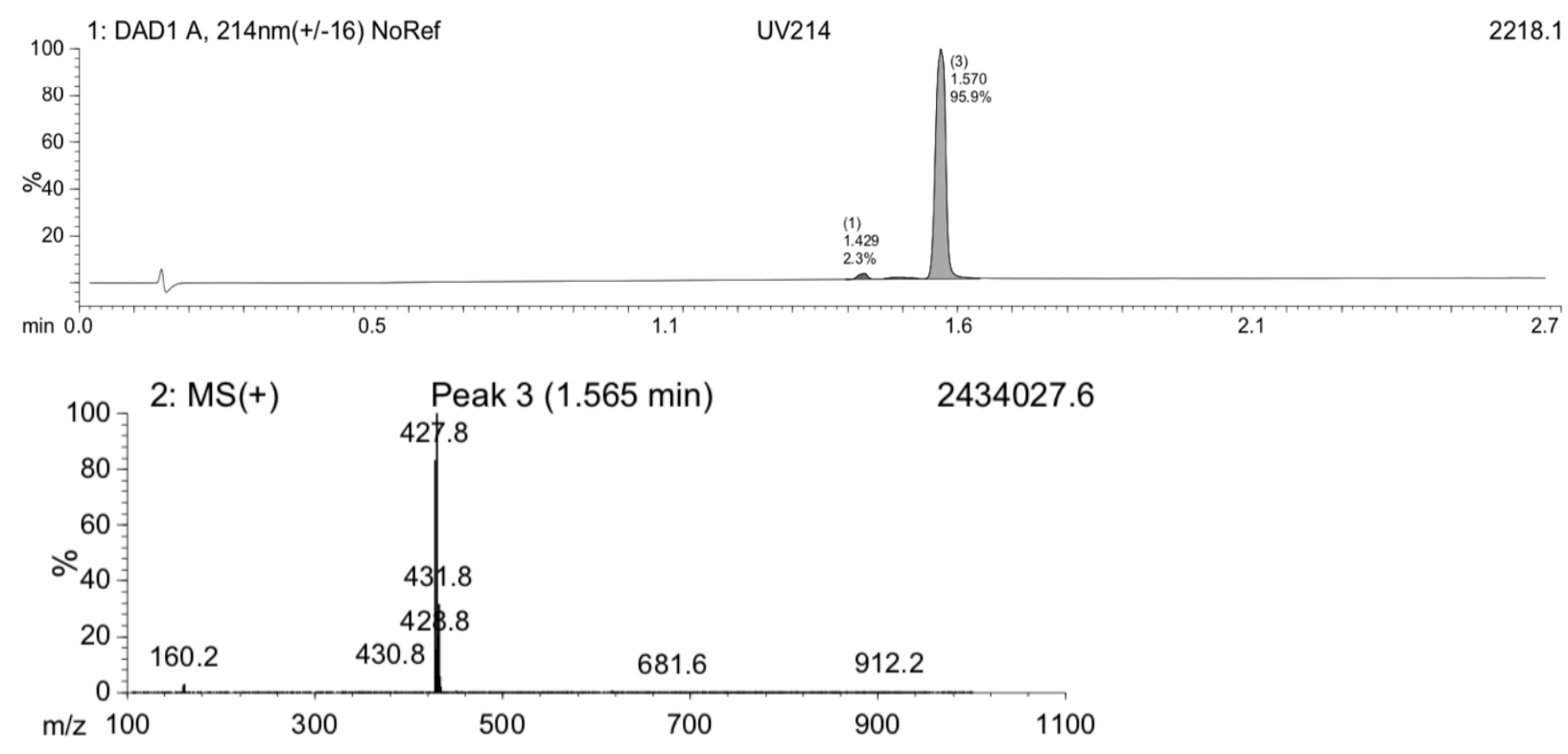

$\underline{\text { HPLC trace of compound 2d }}$

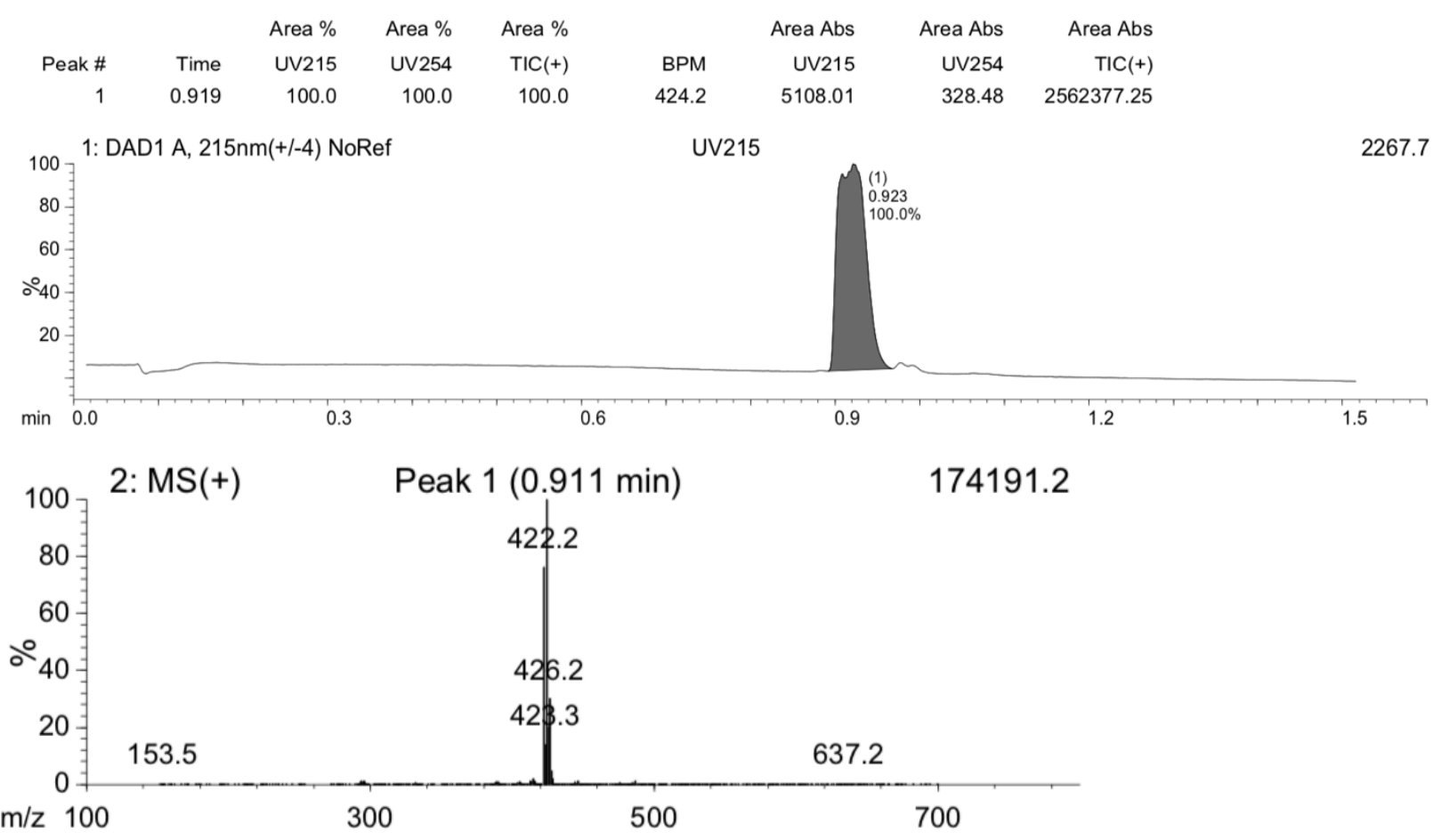


HPLC trace of compound 2e

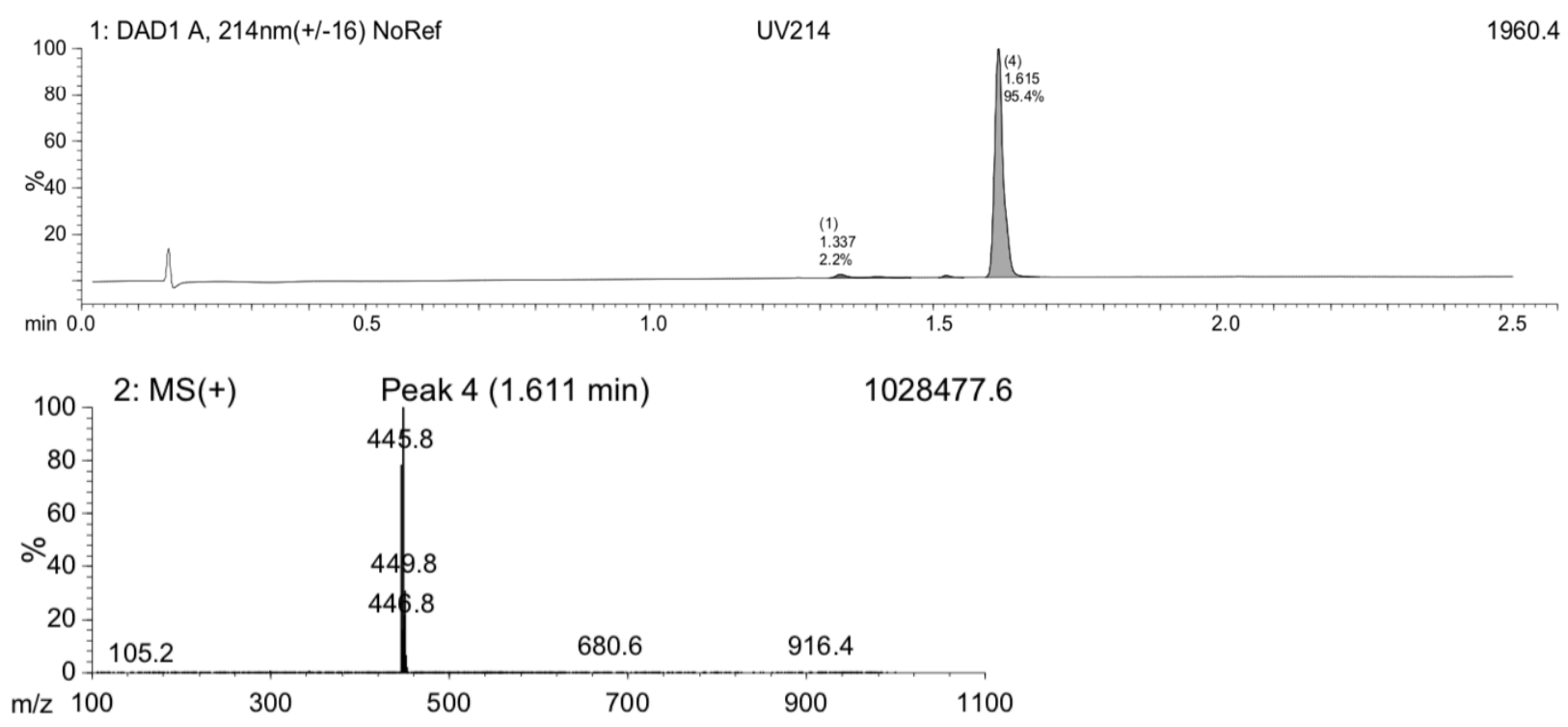

$\underline{\text { HPLC trace of compound } \mathbf{2 f}}$

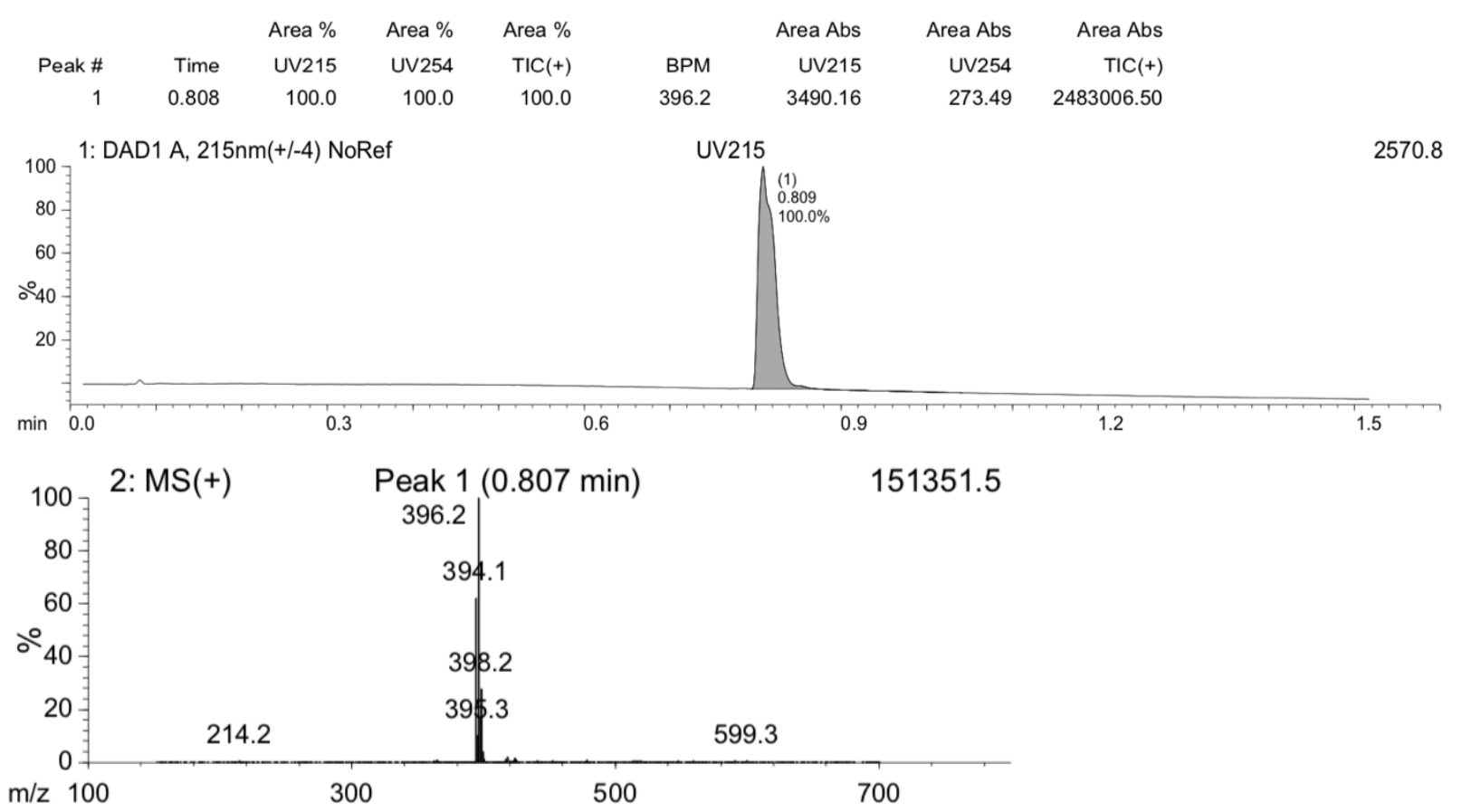


HPLC trace of compound $\mathbf{2 g}$

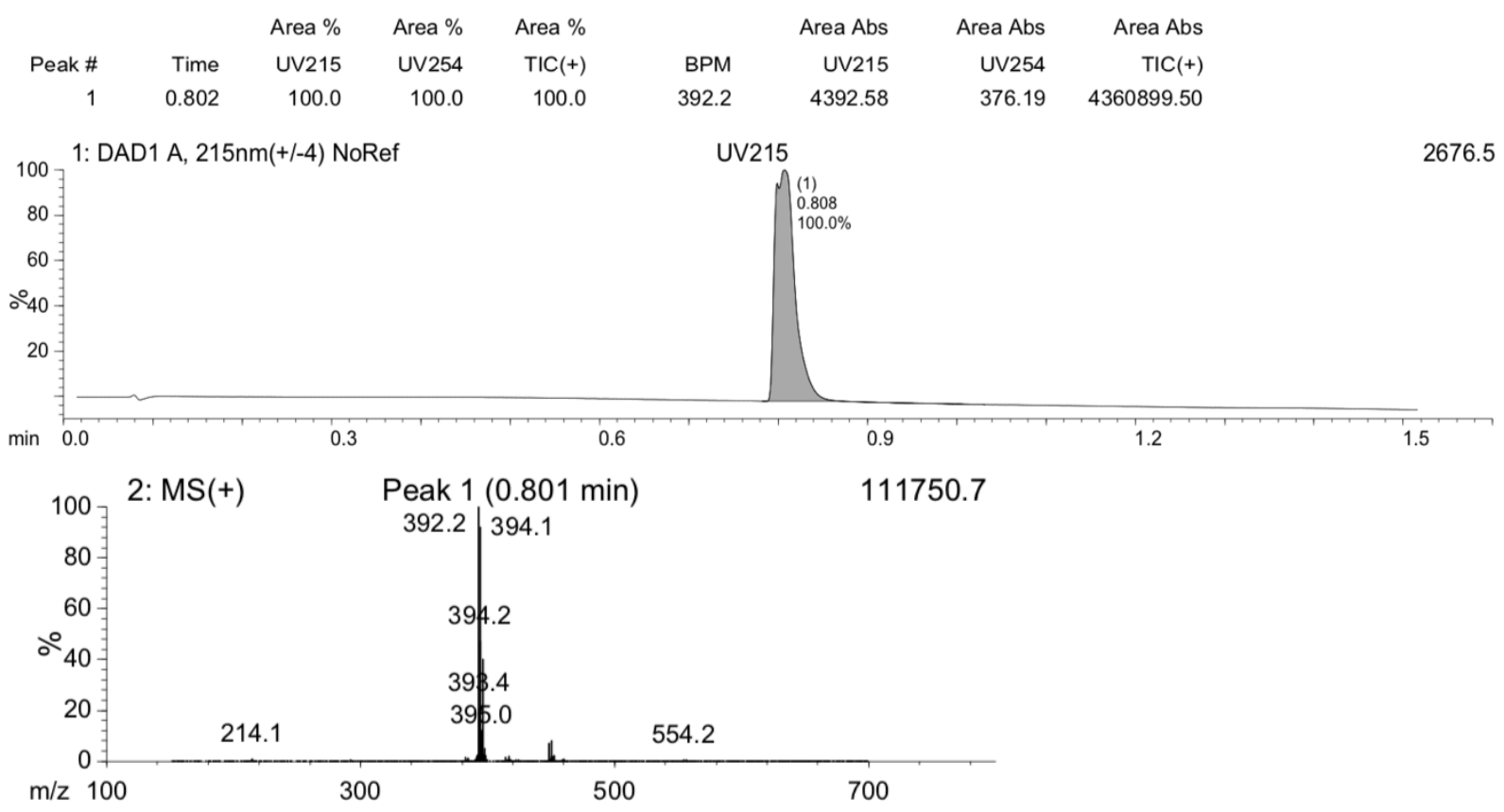

$\underline{\text { HPLC trace of compound } \mathbf{2 h}}$

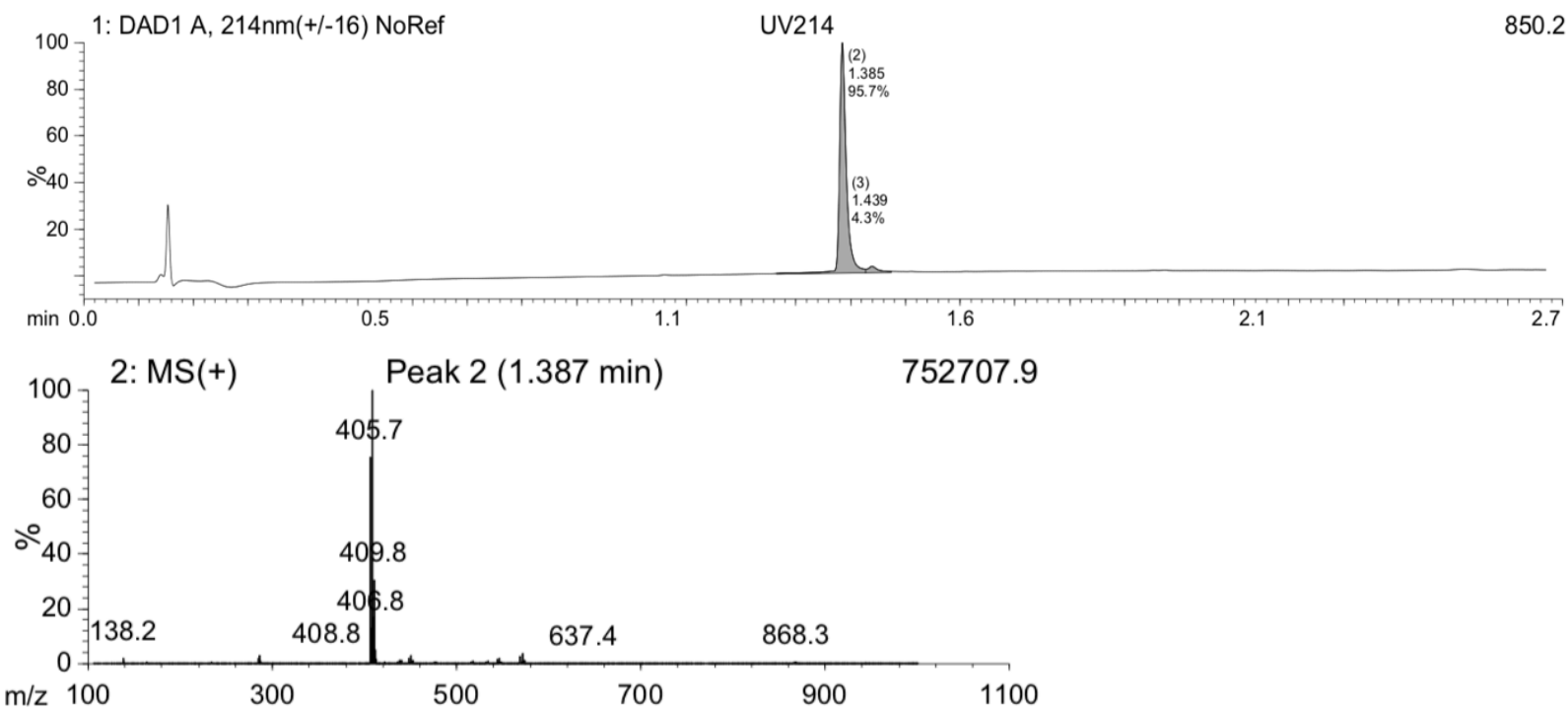


HPLC trace of compound $\mathbf{2 i}$

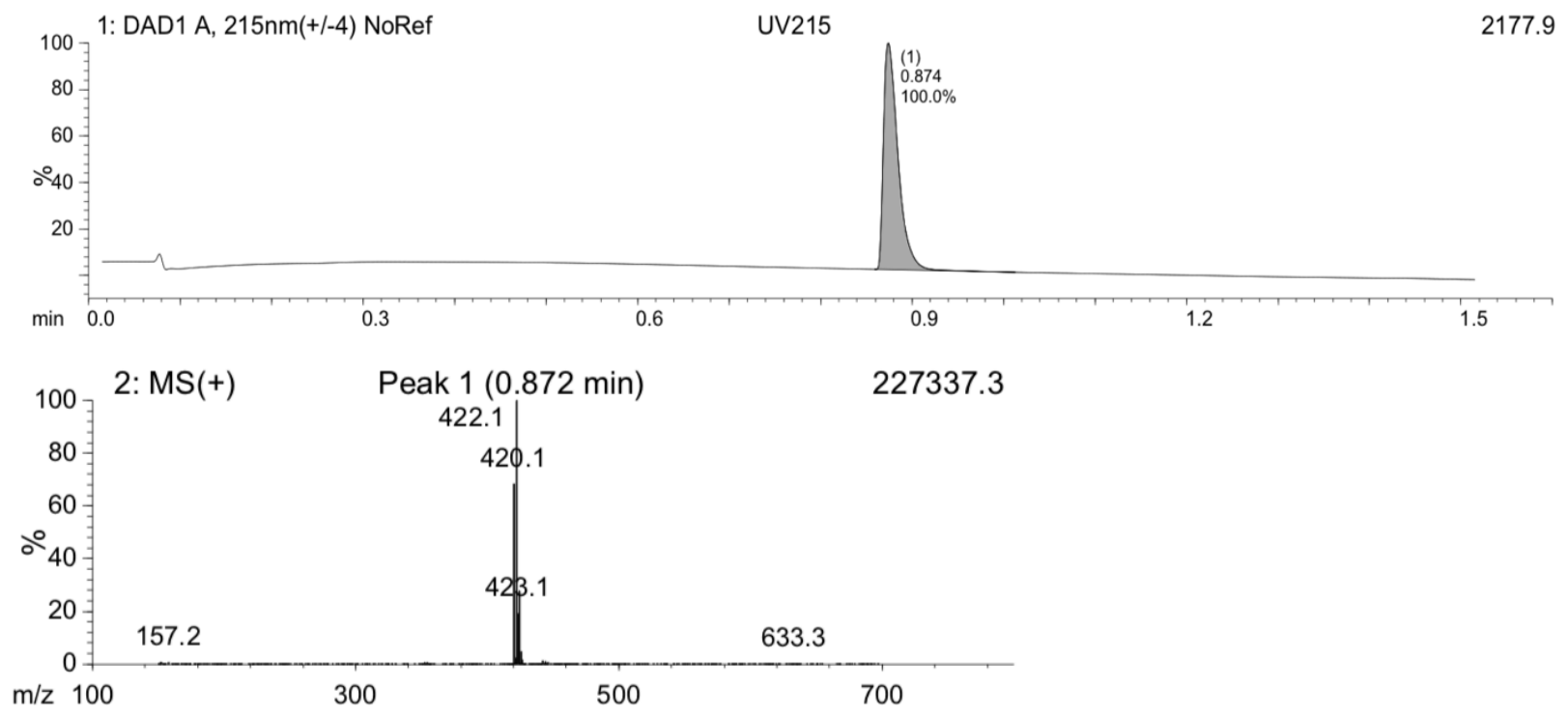

HPLC trace of compound $\mathbf{2 j}$
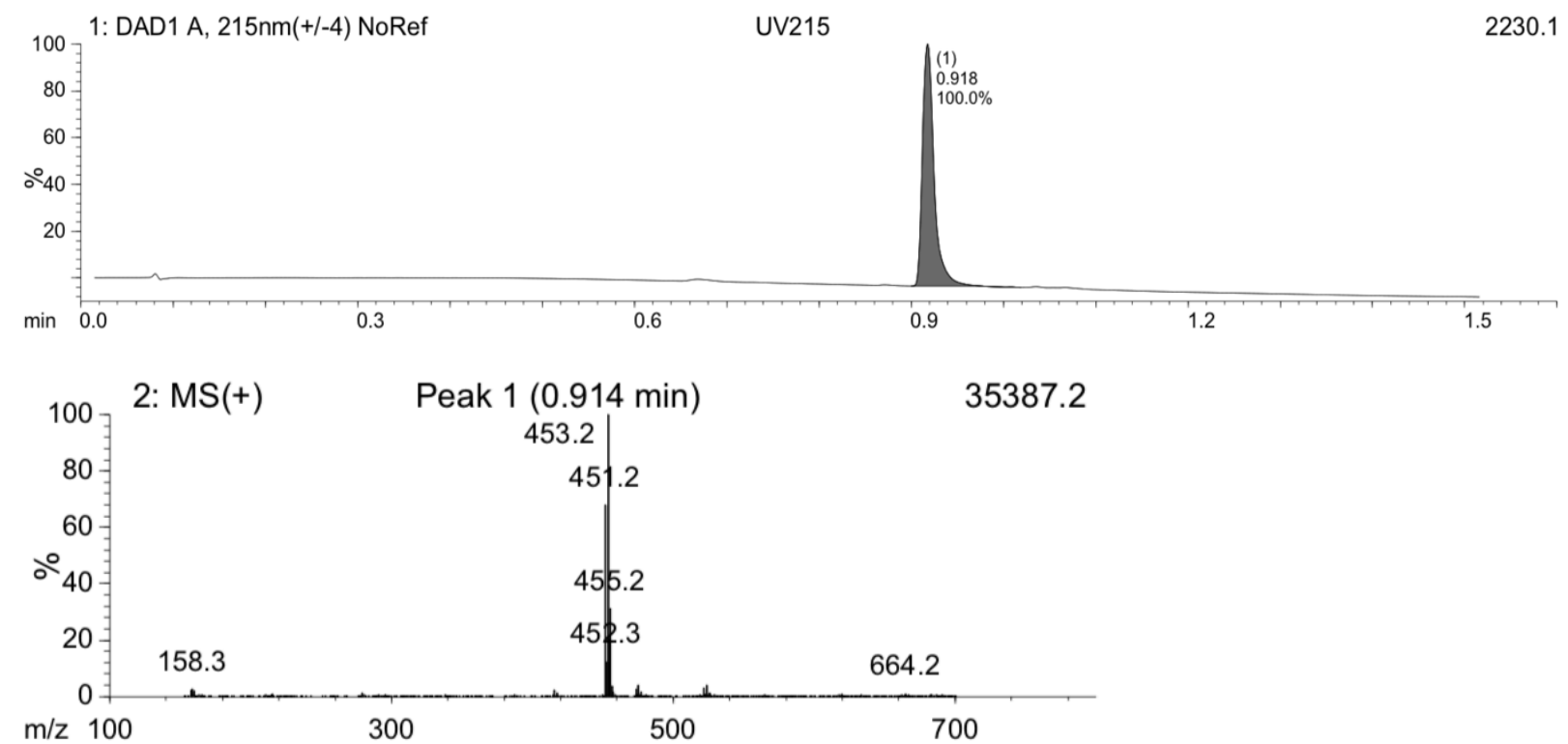
HPLC trace of compound $\mathbf{2 k}$

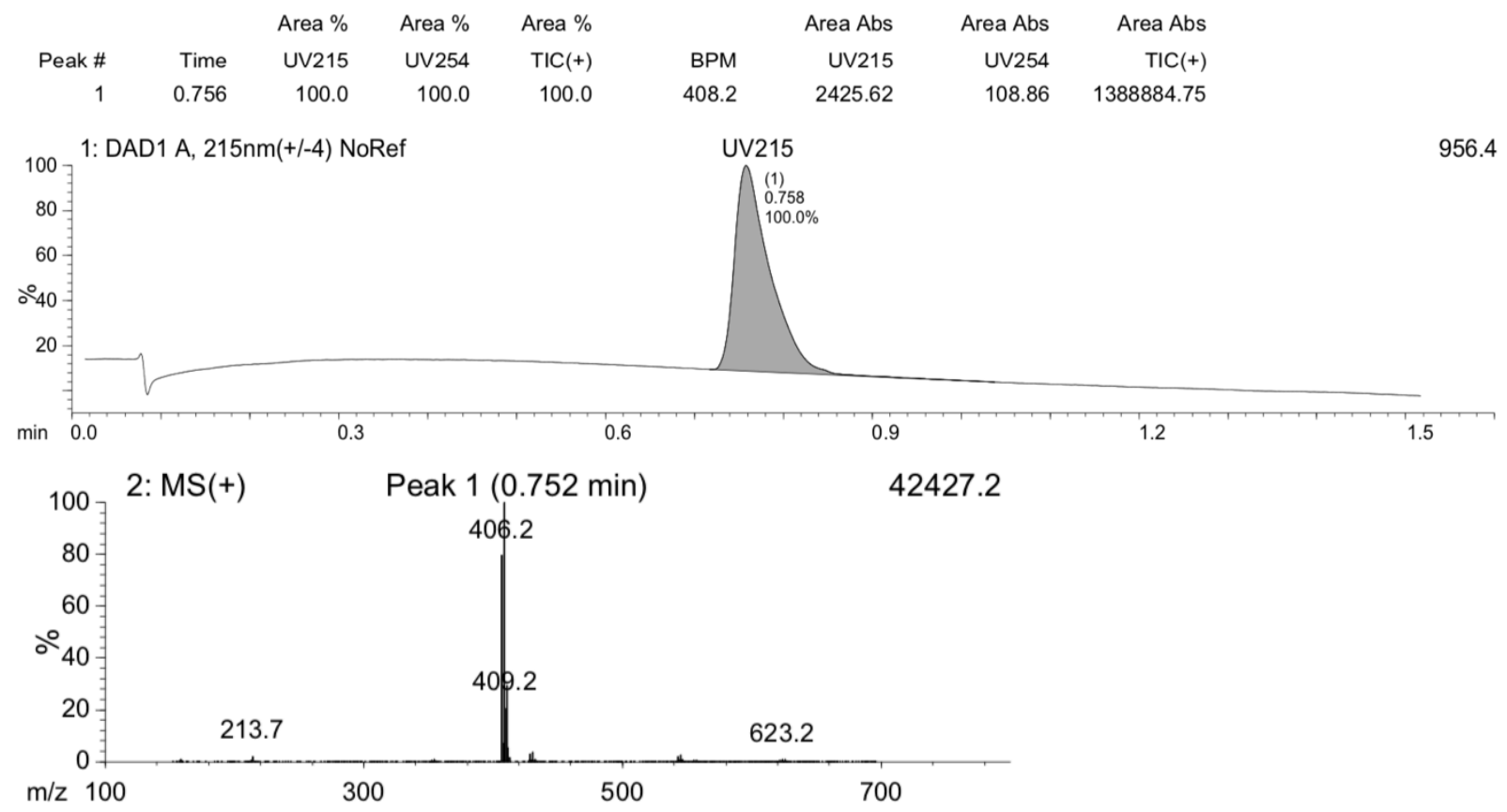

$\underline{\text { HPLC trace of compound } \mathbf{2 I}}$

$\begin{array}{rrrrrrrrr} & & \text { Area \% } & \text { Area \% } & \text { Area \% } & & \text { Area Abs } & \text { Area Abs } & \text { Area Abs } \\ \text { Peak \# } & \text { Time } & \text { UV215 } & \text { UV254 } & \text { TIC }(+) & \text { BPM } & \text { UV215 } & \text { UV254 } & \text { TIC }(+) \\ 1 & 1.108 & 100.0 & 86.3 & 100.0 & 423.1 & 4385.74 & 83.92 & 3497031.50 \\ 2 & 1.129 & 0.0 & 13.7 & 0.0 & 556.3 & 0 & 13.33 & 0\end{array}$
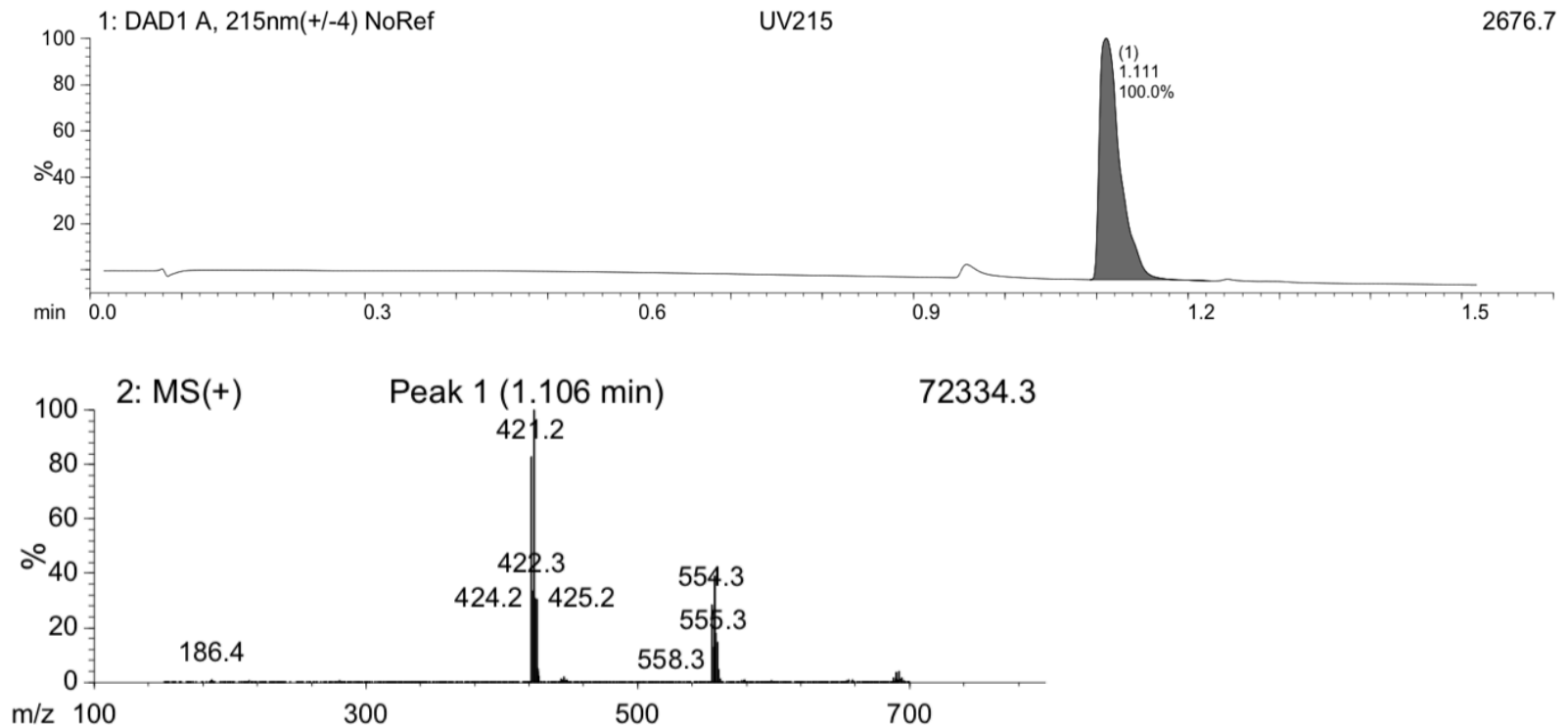
$\underline{\text { HPLC trace of compound } \mathbf{2 m}}$

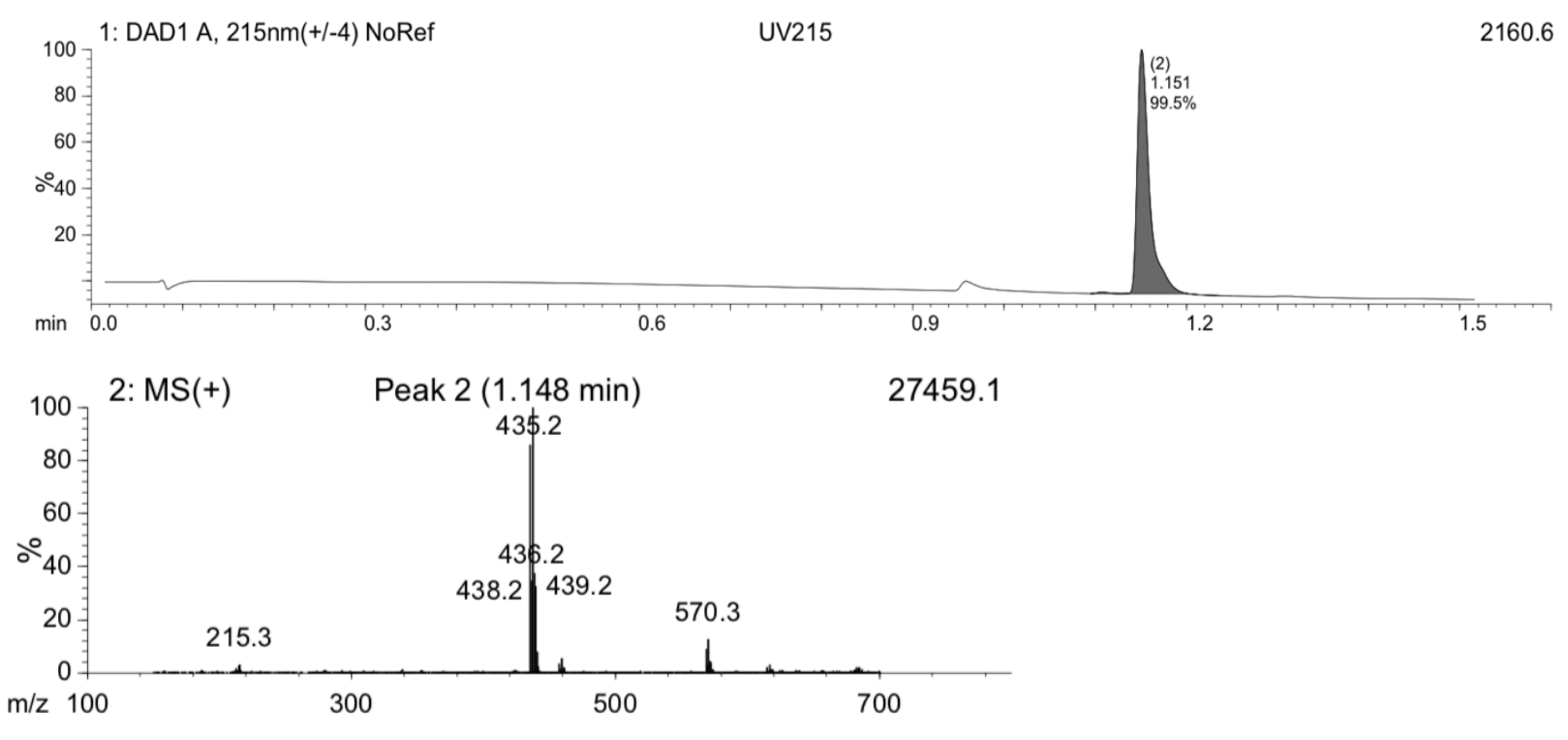

$\underline{\text { HPLC trace of compound 2n }}$

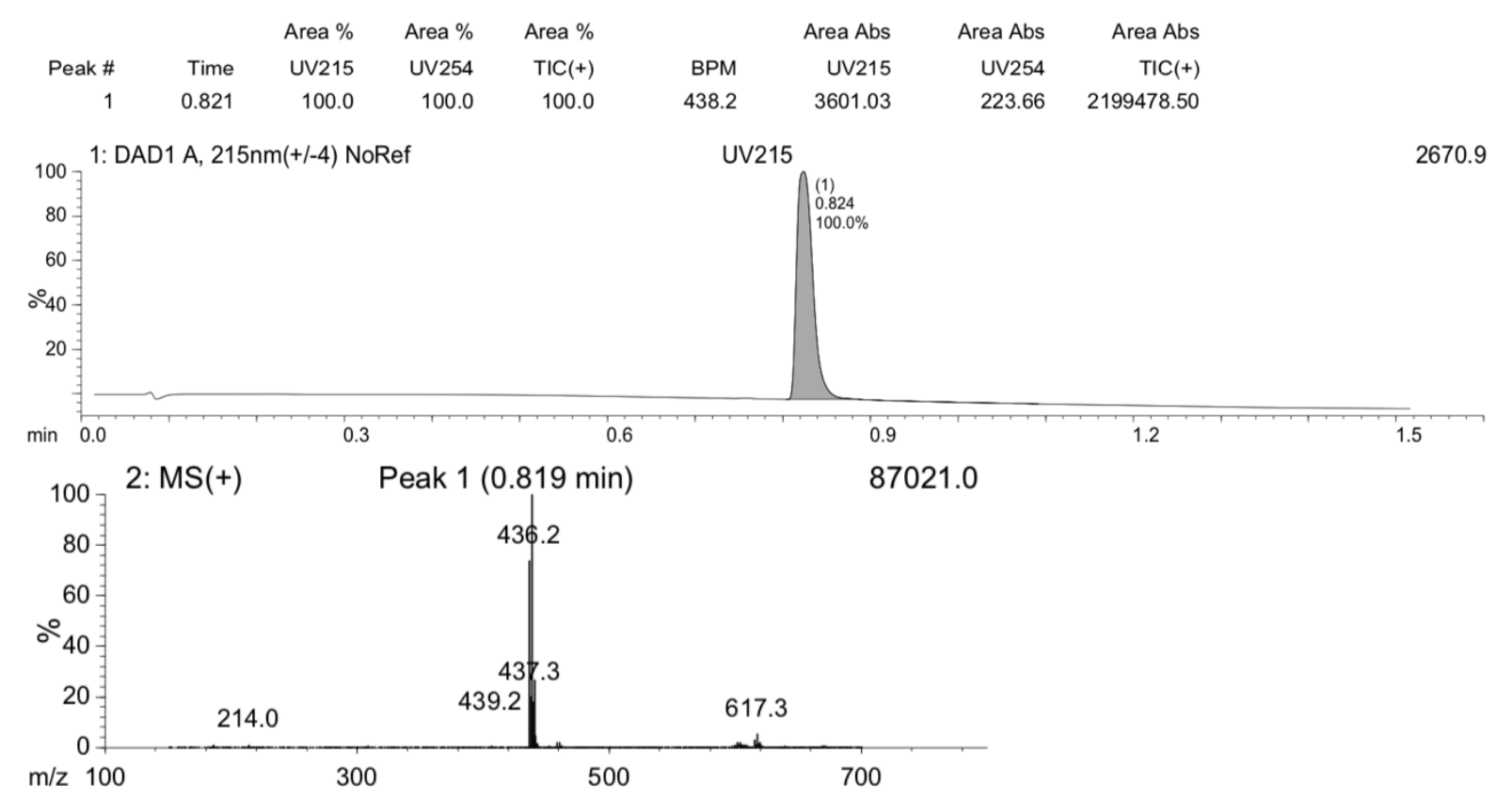


HPLC trace of compound 20

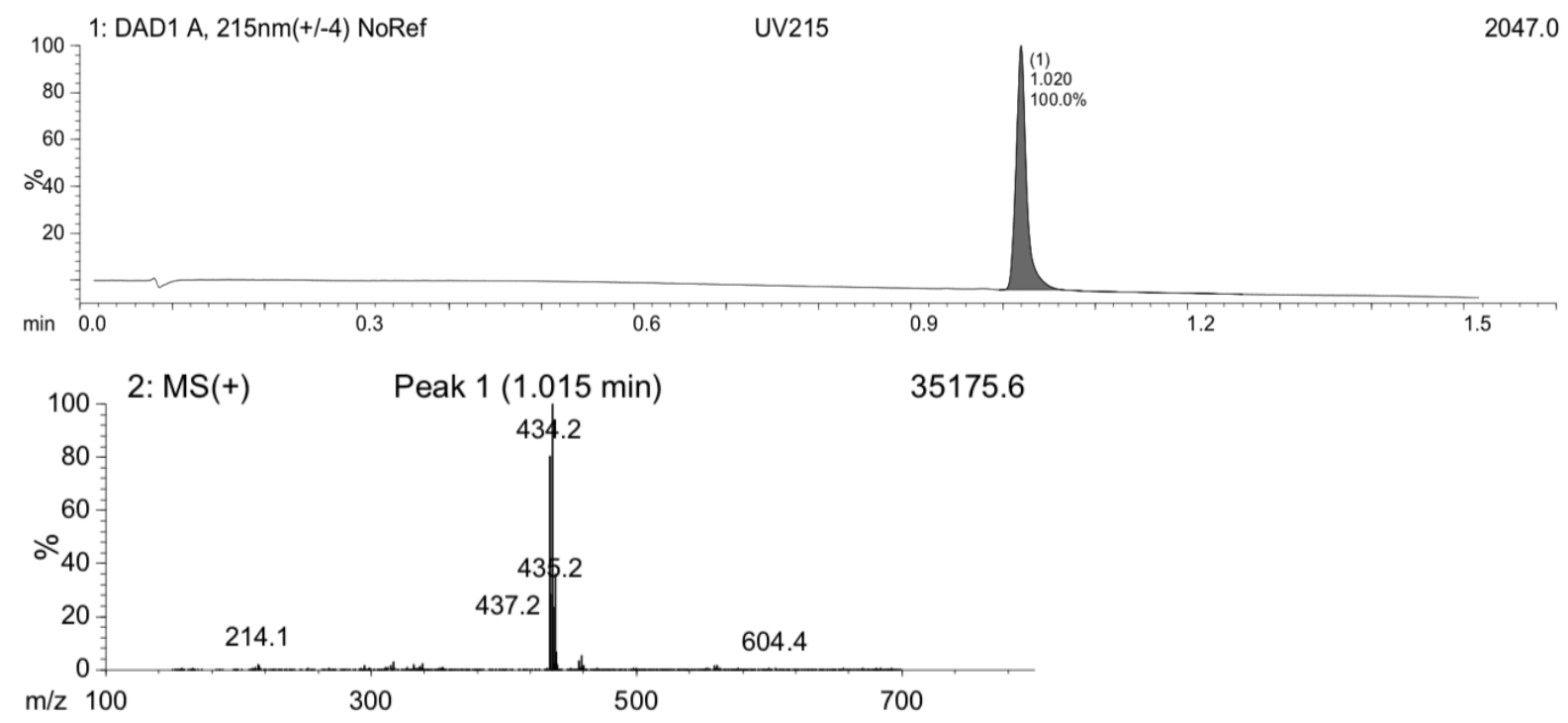

HPLC trace of compound 2p

$\begin{array}{rrrrrrrrr} & & \text { Area } \% & \text { Area \% } & \text { Area } \% & & \text { Area Abs } & \text { Area Abs } & \text { Area Abs } \\ \text { Peak \# } & \text { Time } & \text { UV215 } & \text { UV254 } & \text { TIC }(+) & \text { BPM } & \text { UV215 } & \text { UV254 } & \text { TIC }(+) \\ 1 & 1.066 & 100.0 & 100.0 & 100.0 & 450.3 & 1970.88 & 224.59 & 2384407.50\end{array}$
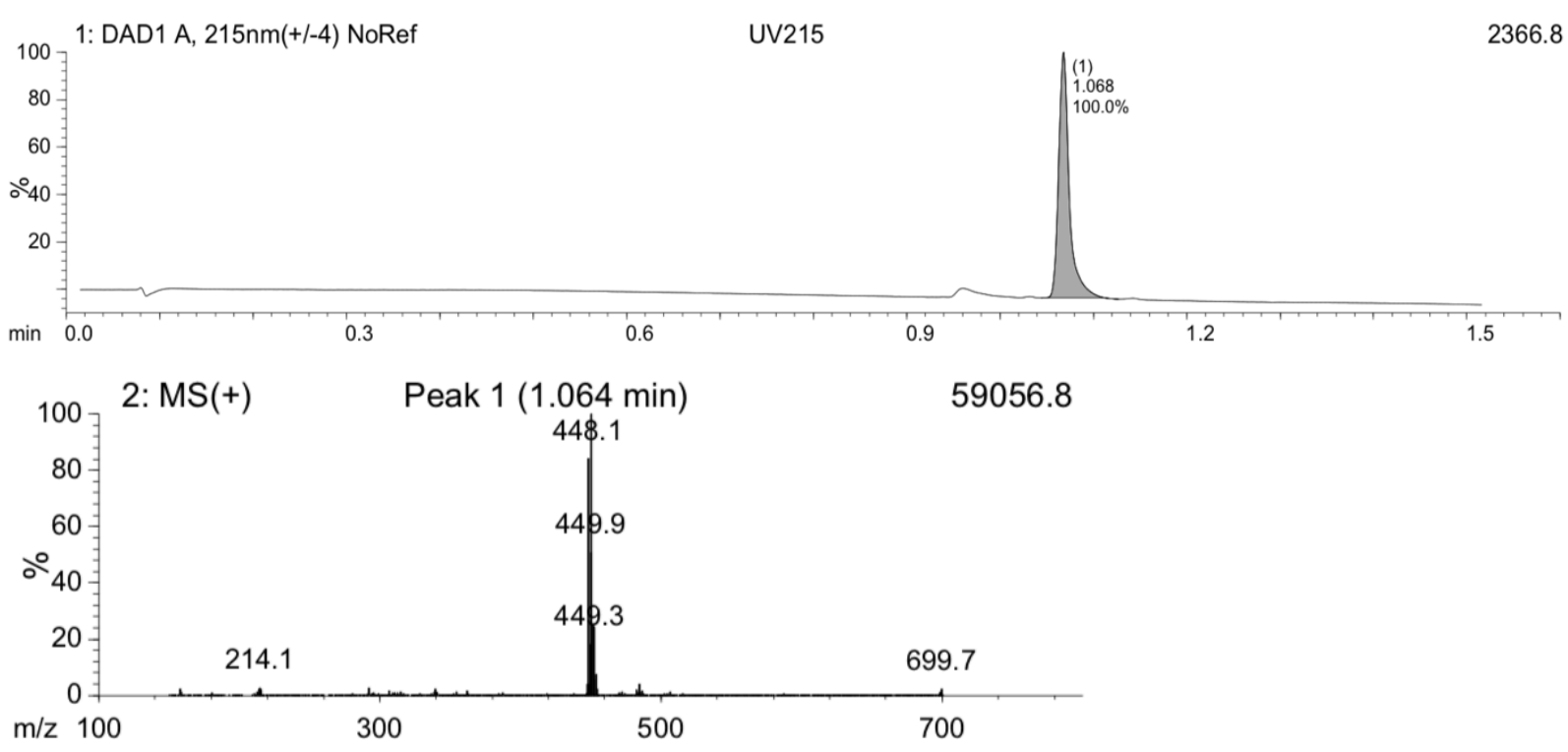
HPLC trace of compound 3a
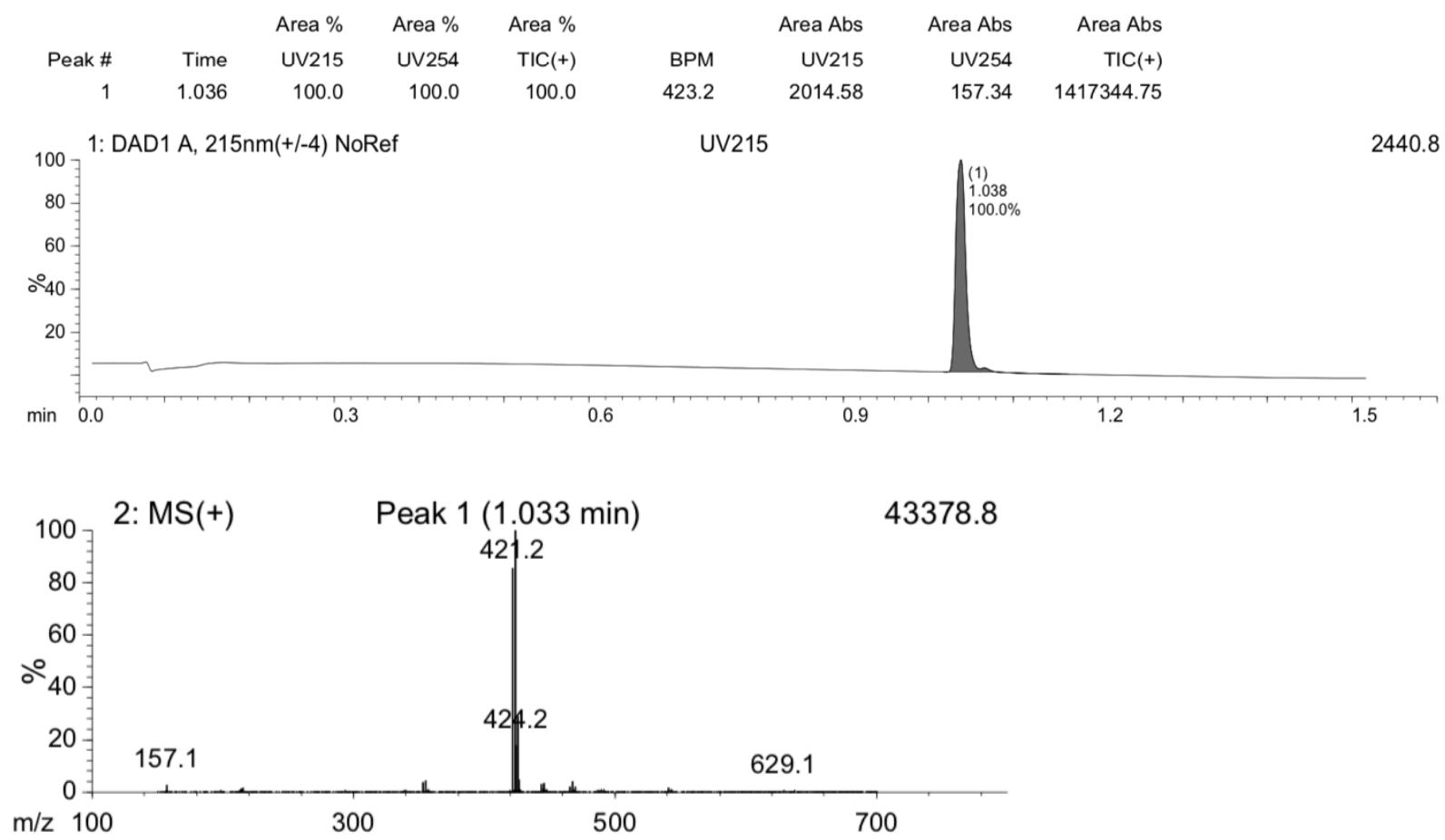

HPLC trace of compound $\mathbf{3 b}$

\begin{tabular}{crrrrrrrr} 
& & Area $\%$ & Area $\%$ & Area $\%$ & & Area Abs & Area Abs & Area Abs \\
Peak \# & Time & UV215 & UV254 & TIC $(+)$ & BPM & UV215 & UV254 & TIC $(+)$ \\
1 & 1.228 & 100.0 & 100.0 & 100.0 & 422.2 & 2463.39 & 1130.80 & 3168538.50 \\
1: DAD1 A, 215nm(+/-4) NoRef & \multicolumn{7}{c}{ UV215 }
\end{tabular}
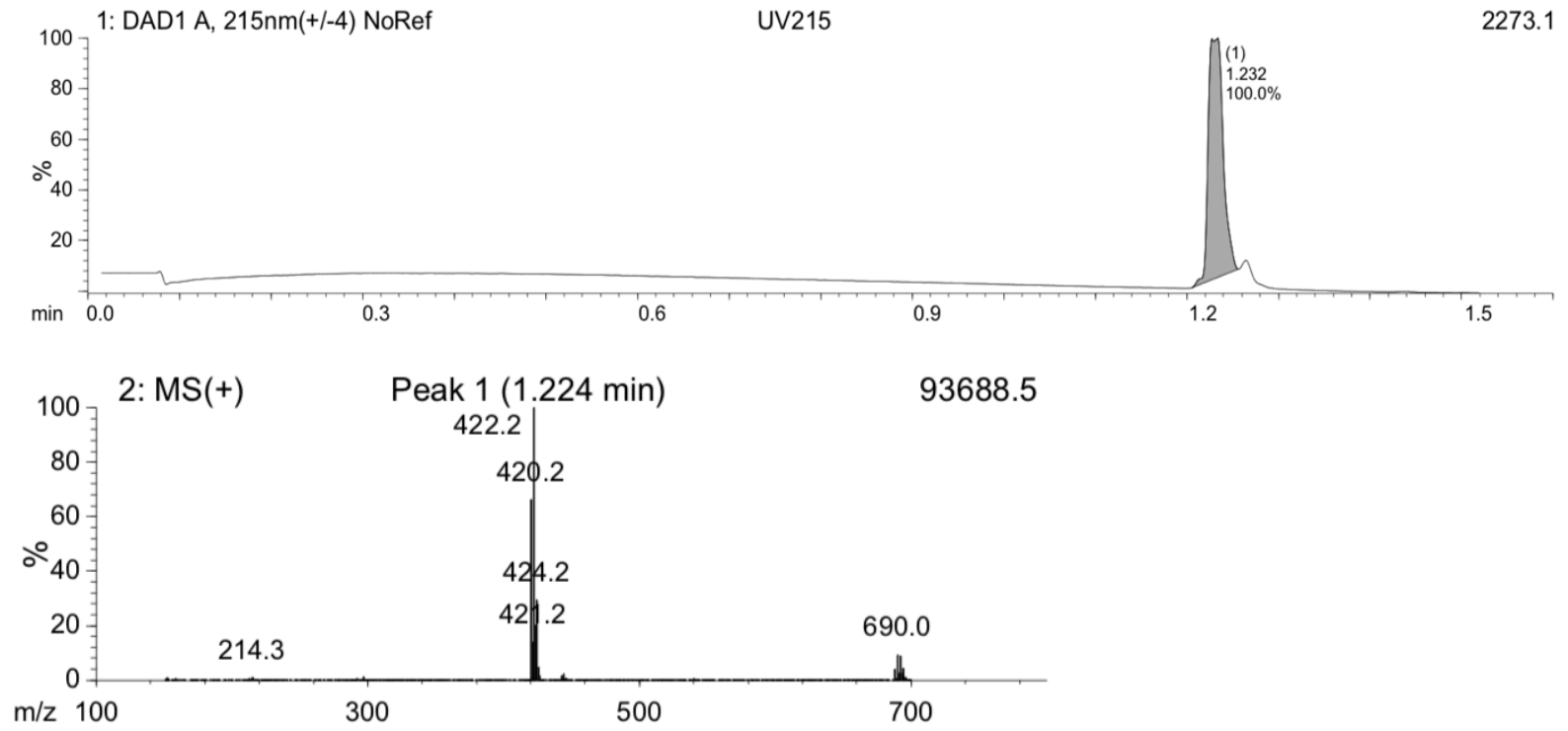
$\underline{\text { HPLC trace of compound 3c }}$
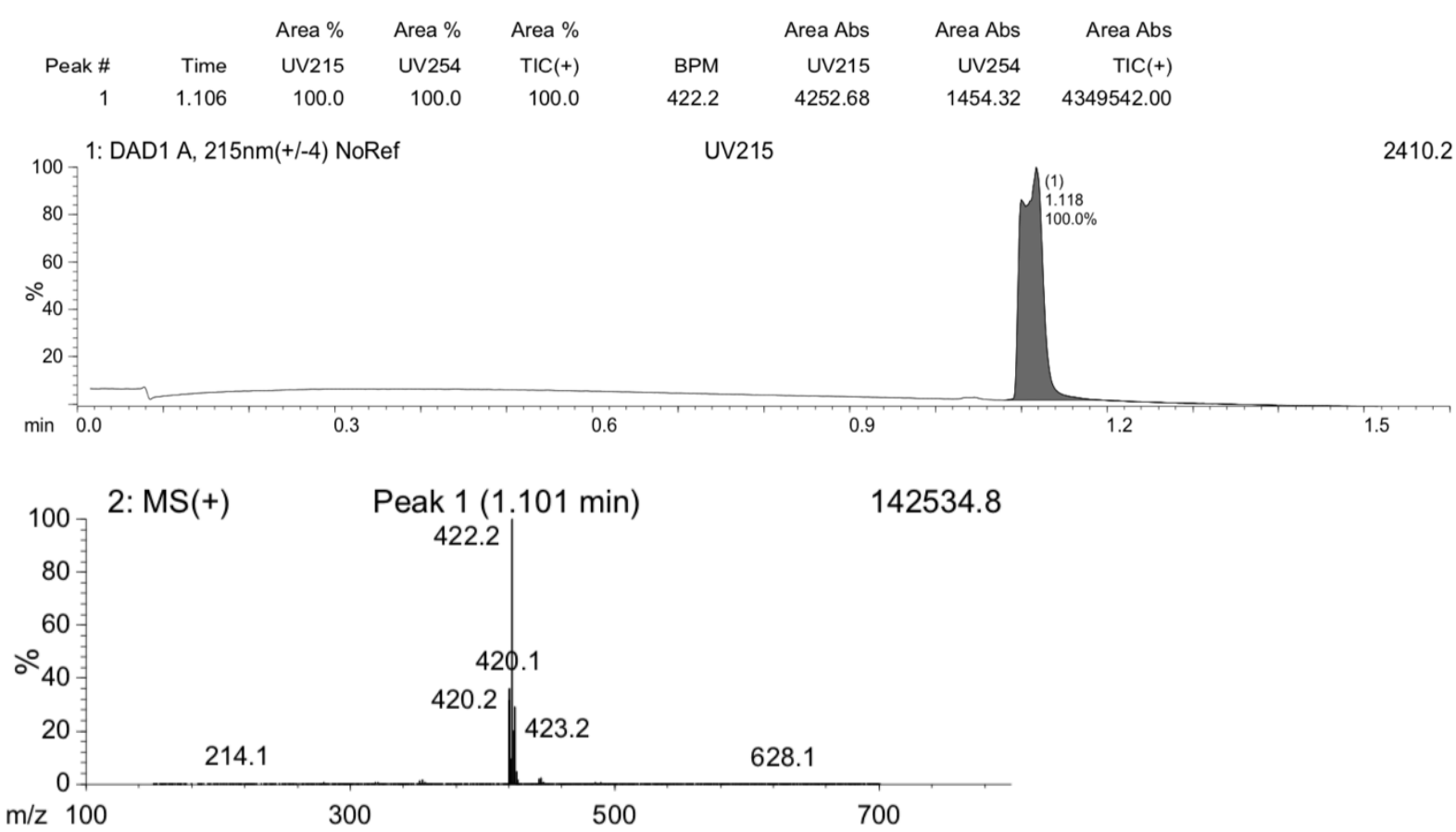

HPLC trace of compound 3d

$\begin{array}{rrrrrrrrr} & & \text { Area } \% & \text { Area } \% & \text { Area } \% & & \text { Area Abs } & \text { Area Abs } & \text { Area Abs } \\ \text { Peak \# } & \text { Time } & \text { UV215 } & \text { UV254 } & \text { TIC }(+) & \text { BPM } & \text { UV215 } & \text { UV254 } & \text { TIC }(+) \\ 1 & 1.047 & 100.0 & 100.0 & 100.0 & 422.2 & 3672.04 & 702.30 & 3168807.75\end{array}$
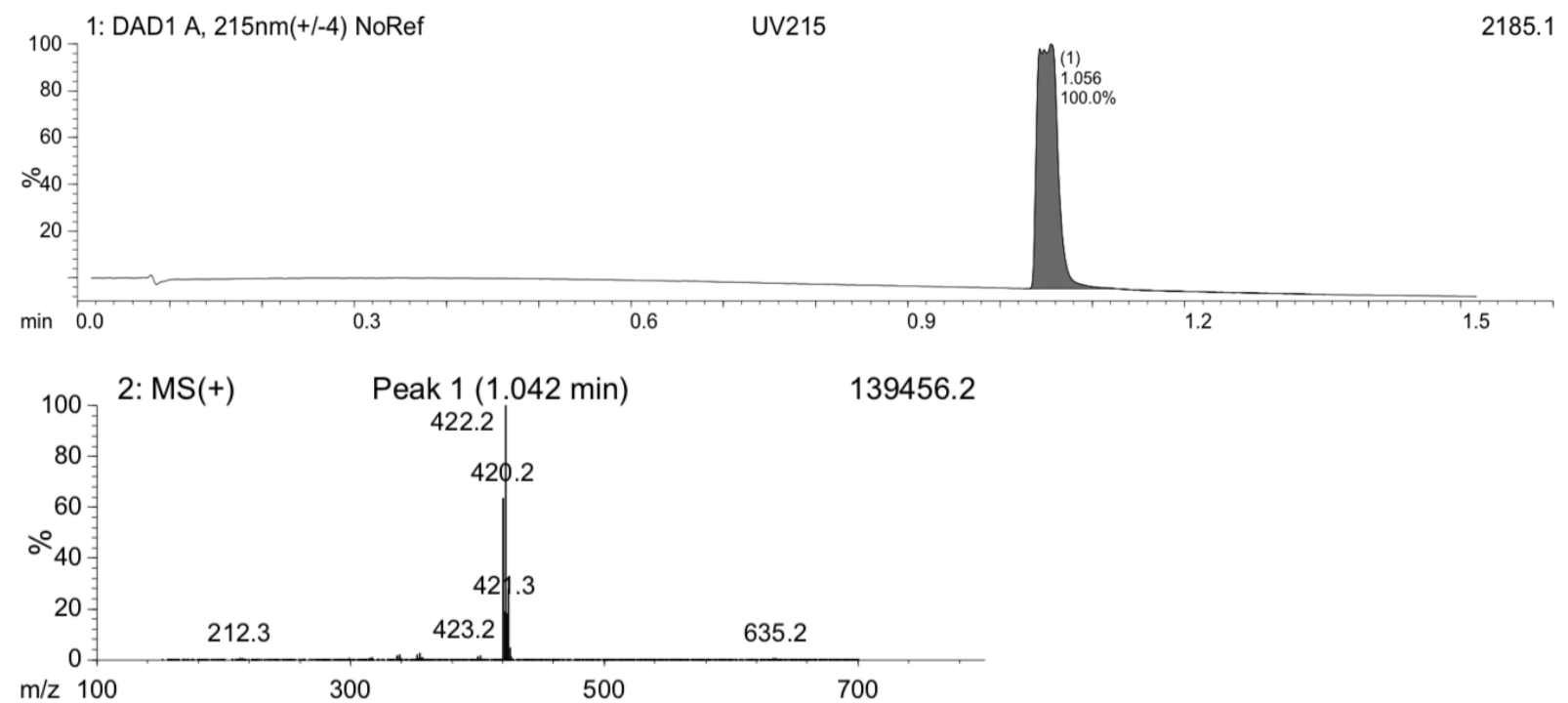
HPLC trace of compound 3e

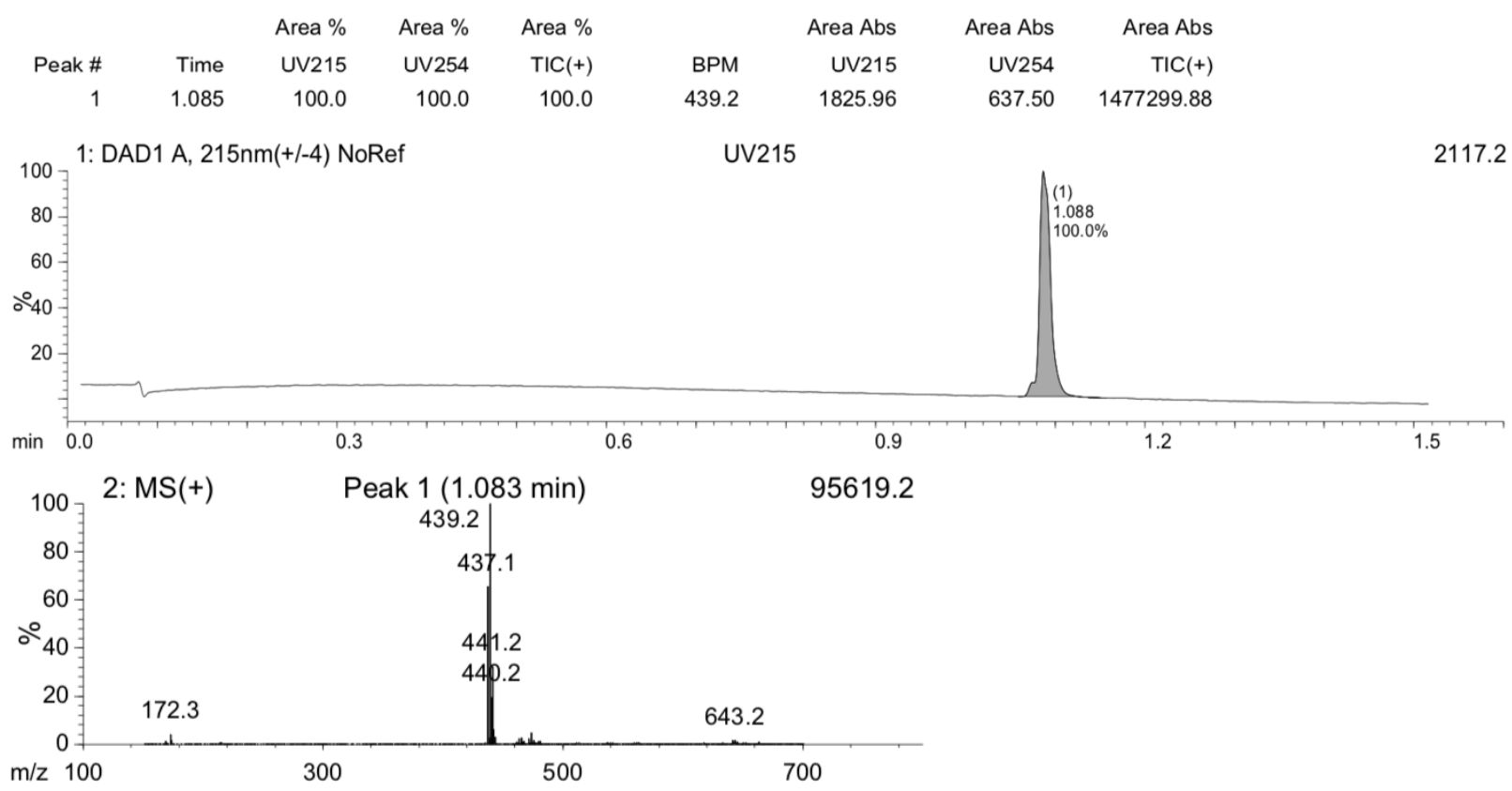

HPLC trace of compound $\mathbf{3 f}$

$\begin{array}{rrrrrrrrr} & & \text { Area \% } & \text { Area \% } & \text { Area \% } & & \text { Area Abs } & \text { Area Abs } & \text { Area Abs } \\ \text { Peak \# } & \text { Time } & \text { UV215 } & \text { UV254 } & \text { TIC }(+) & \text { BPM } & \text { UV215 } & \text { UV254 } & \text { TIC }(+) \\ 1 & 0.081 & 1.0 & 0.0 & 9.8 & 213.5 & 31.76 & 0 & 85085.08 \\ 2 & 1.079 & 1.3 & 2.0 & 90.2 & 421.1 & 38.86 & 20.47 & 783674.06 \\ 3 & 1.098 & 97.7 & 98.0 & 0.0 & 421.1 & 3028.03 & 1012.42 & 0\end{array}$

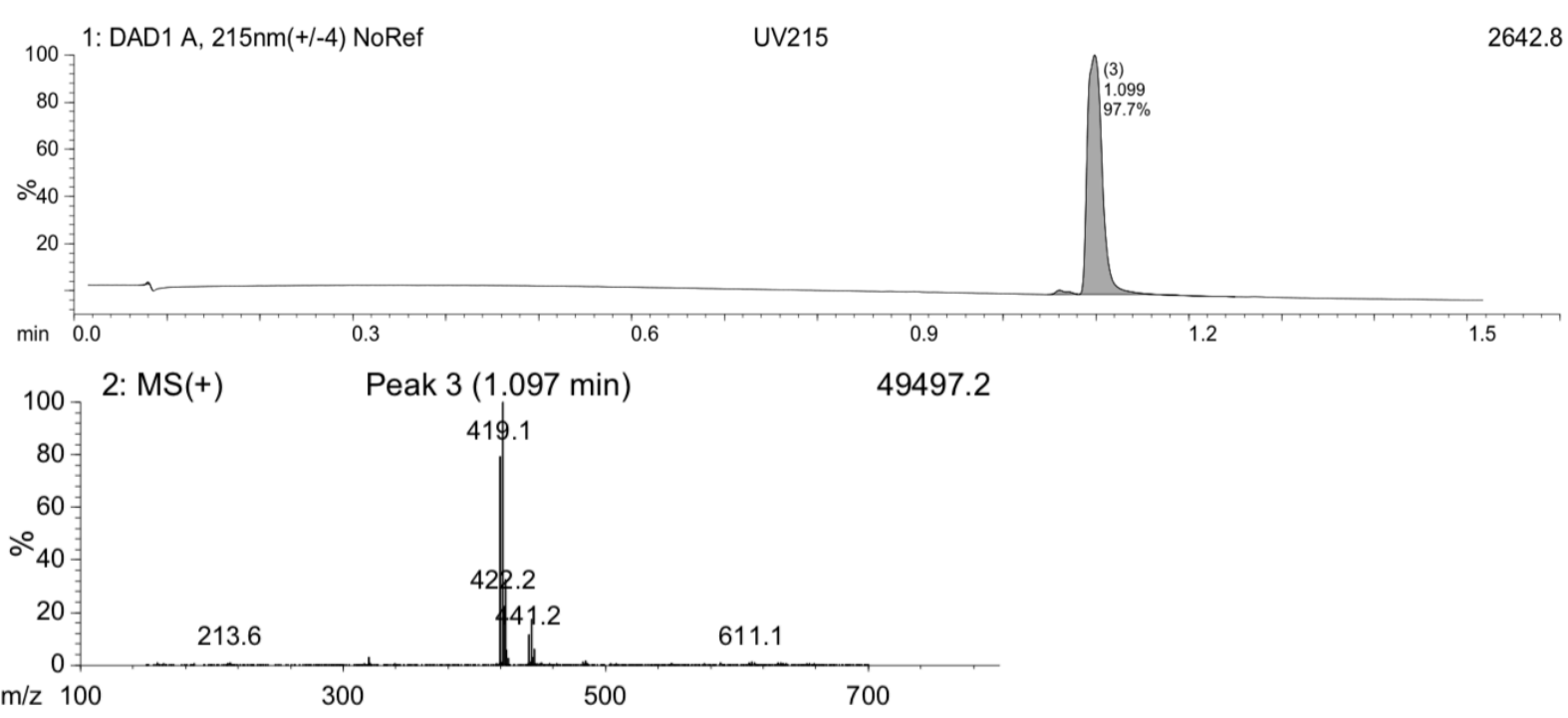


$\underline{\text { HPLC trace of compound } \mathbf{5}}$

$\begin{array}{rrrrrrrrr} & & \text { Area \% } & \text { Area \% } & \text { Area \% } & & \text { Area Abs } & \text { Area Abs } & \text { Area Abs } \\ \text { Peak \# } & \text { Time } & \text { UV215 } & \text { UV254 } & \text { TIC }(+) & \text { BPM } & \text { UV215 } & \text { UV254 } & \text { TIC }(+) \\ 1 & 0.899 & 100.0 & 100.0 & 100.0 & 450.2 & 2417.64 & 116.66 & 4513633.00\end{array}$
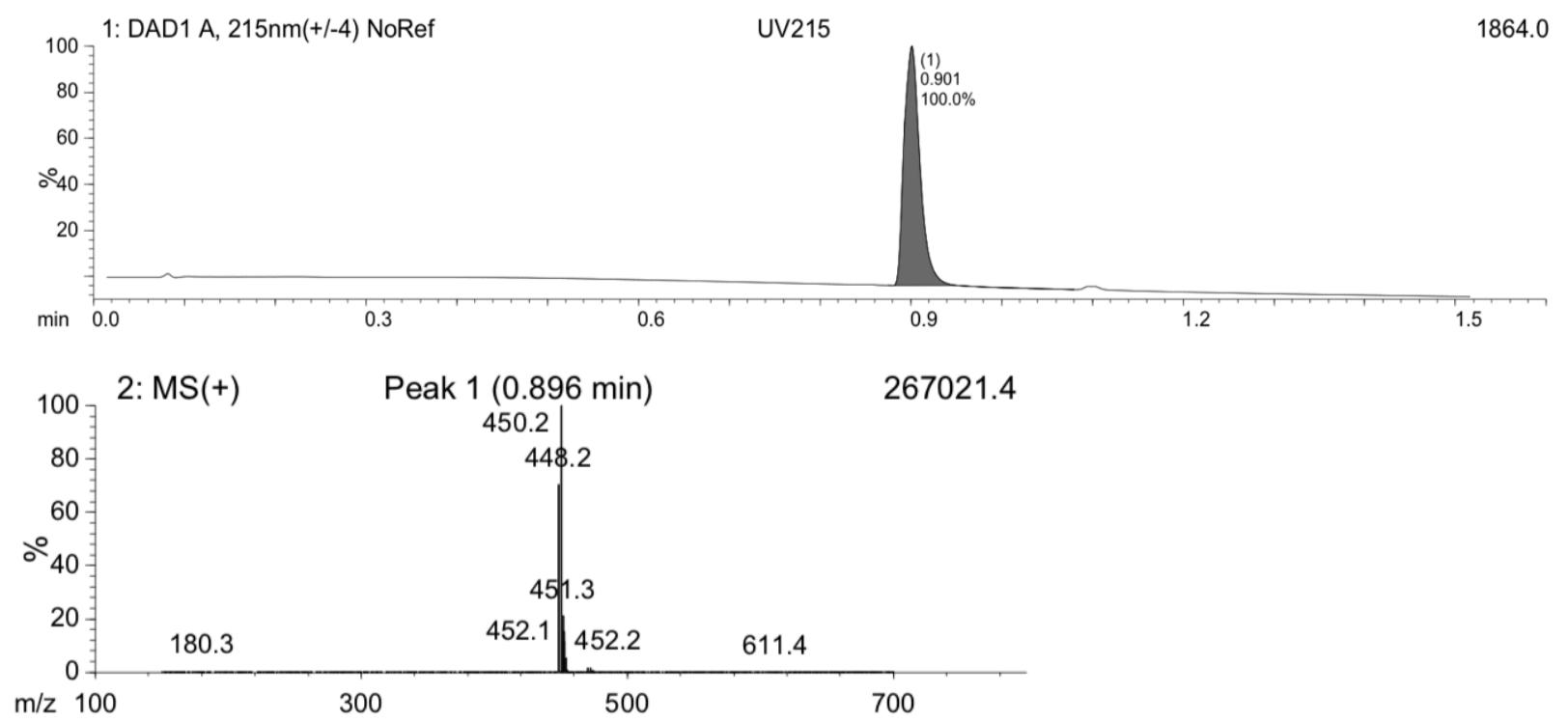

$\underline{\text { HPLC trace of compound } \mathbf{6}}$

$\begin{array}{rrrrrrrrr} & & \text { Area \% } & \text { Area \% } & \text { Area \% } & & \text { Area Abs } & \text { Area Abs } & \text { Area Abs } \\ \text { Peak \# } & \text { Time } & \text { UV215 } & \text { UV254 } & \text { TIC }(+) & \text { BPM } & \text { UV215 } & \text { UV254 } & \text { TIC }(+) \\ 1 & 0.099 & 0.0 & 55.3 & 0.5 & 313.9 & 0 & 856.15 & 20267.69 \\ 2 & 1.127 & 100.0 & 44.7 & 99.5 & 494.2 & 3440.64 & 691.53 & 4406506.50 \\ \text { 1: DAD1 A, 215nm(+/-4) NoRef } & \end{array}$

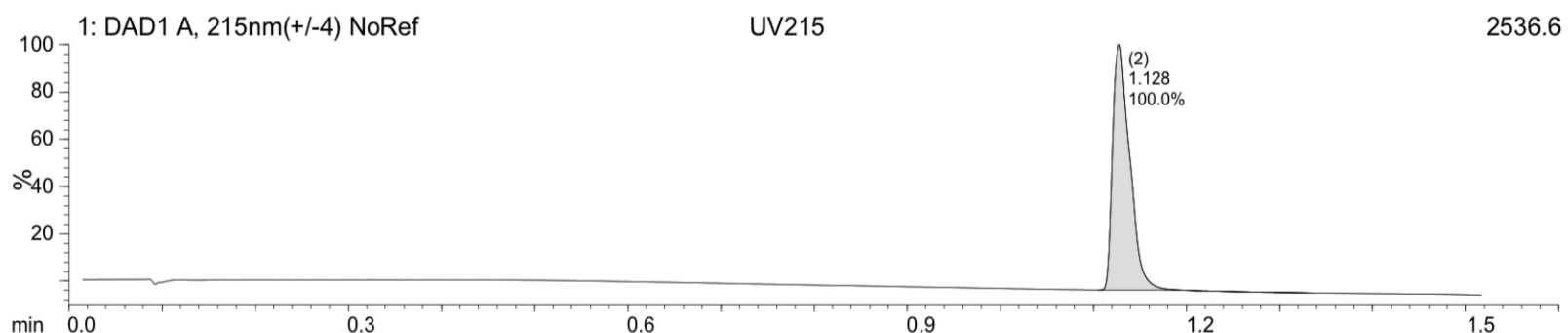

100 2: MS(+) Peak 2 $(1.125 \mathrm{~min}) \quad 97783.9$

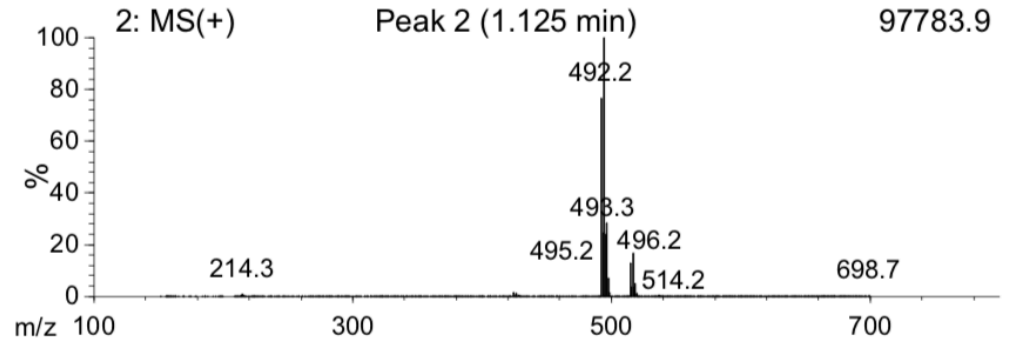


$\underline{\text { HPLC trace of compound } 7}$

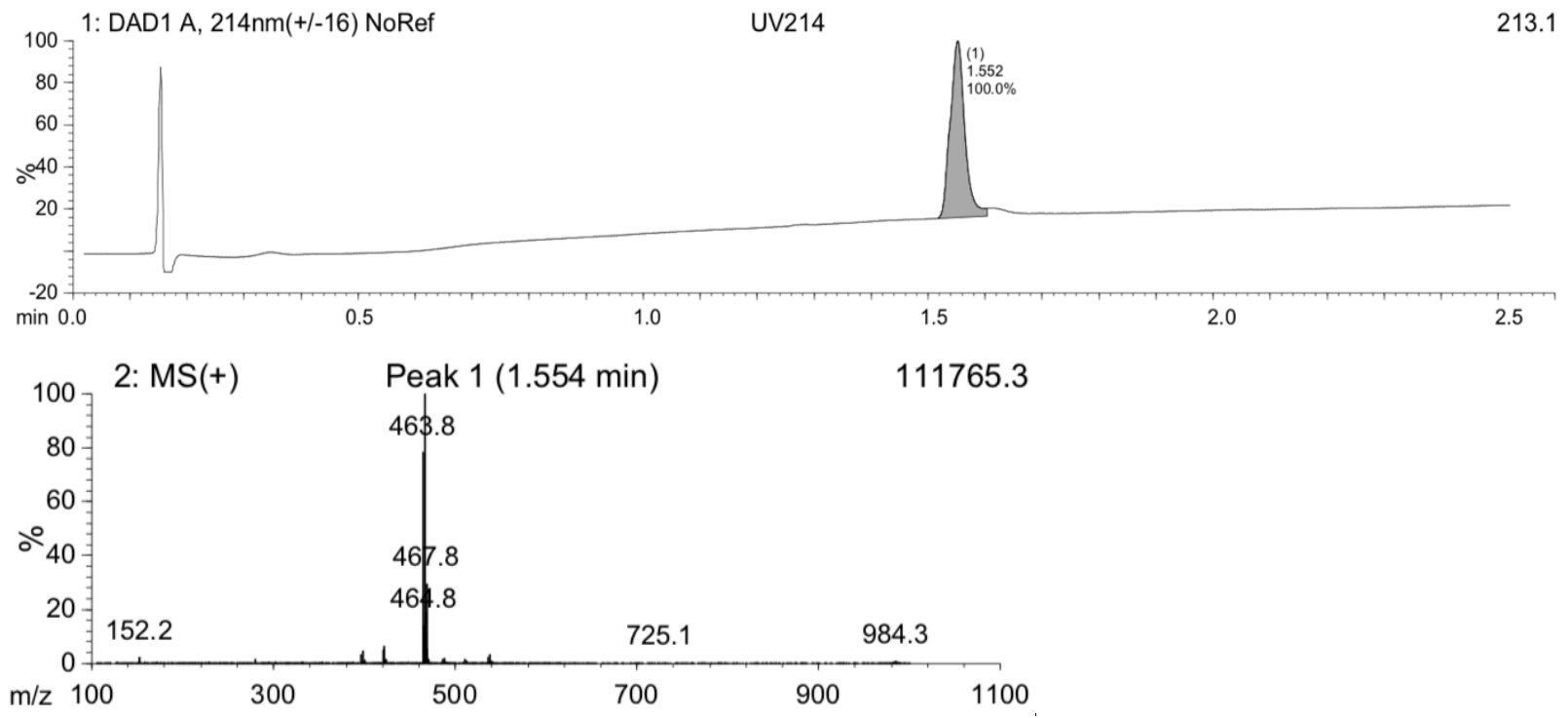

$\underline{\text { HPLC trace of compound } 8}$
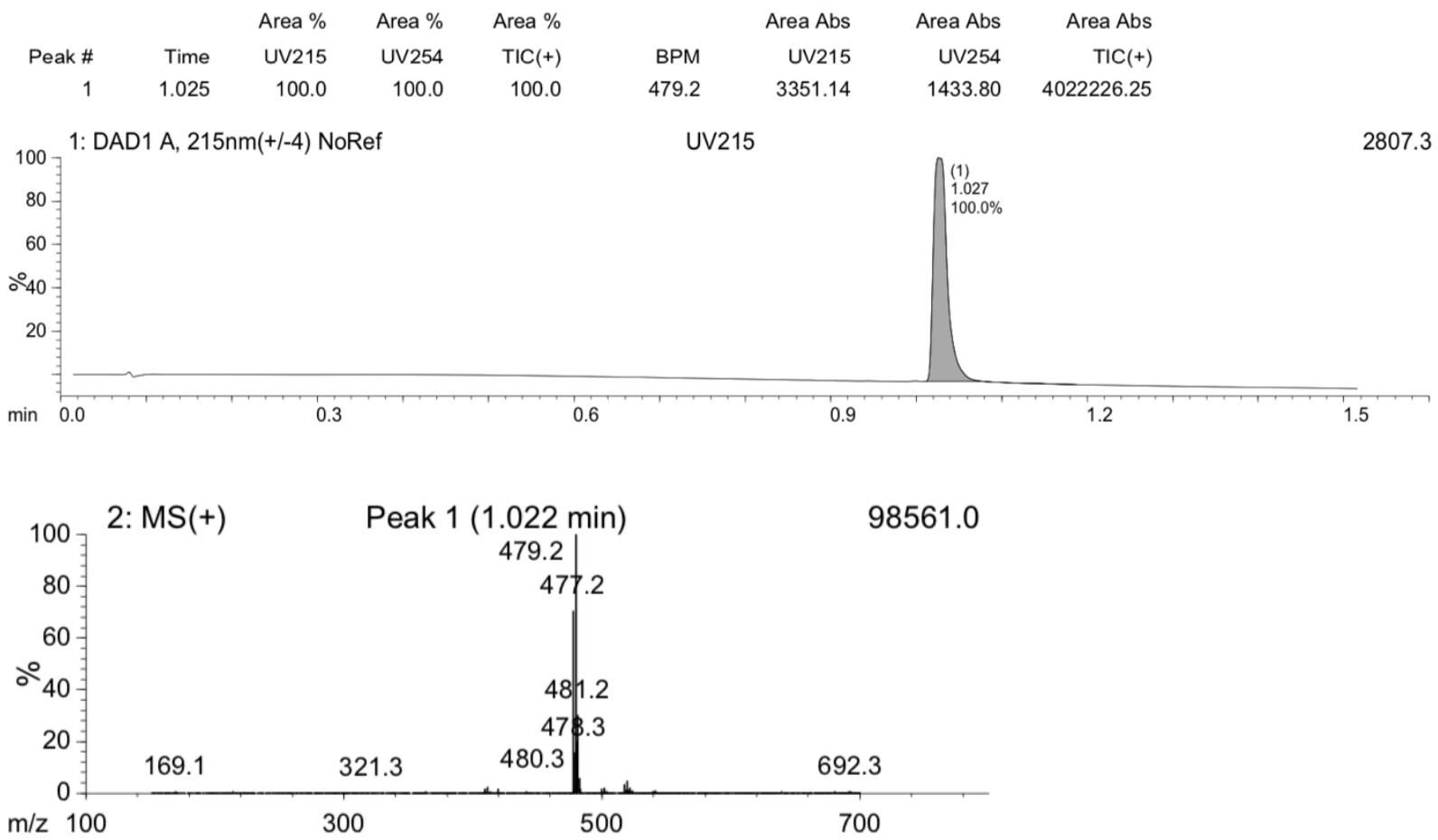
$\underline{\text { HPLC trace of compound } 9}$
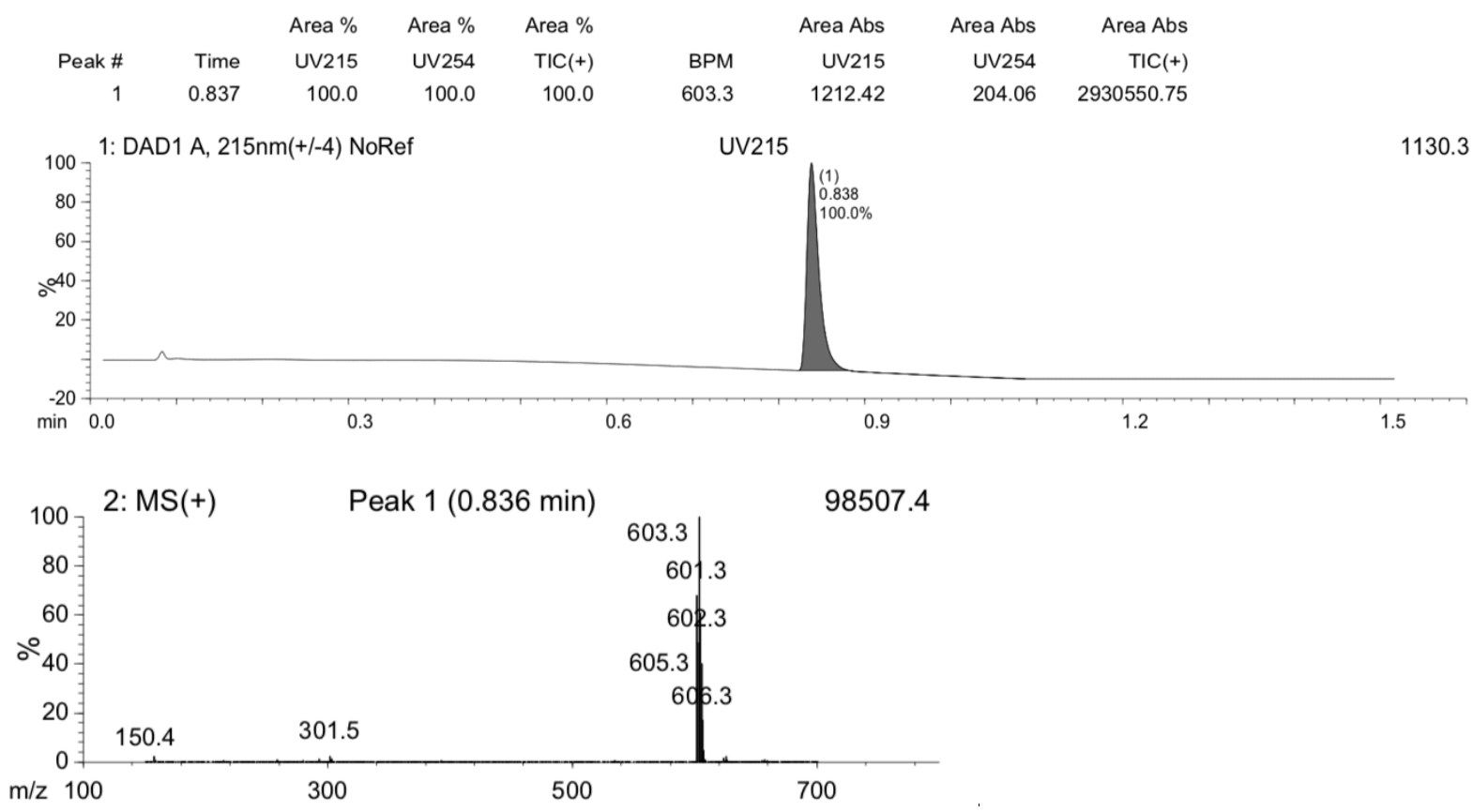

HPLC trace of compound $\mathbf{1 0}$

$\begin{array}{rrrrrrrrr} & & \text { Area \% } & \text { Area \% } & \text { Area \% } & & \text { Area Abs } & \text { Area Abs } & \text { Area Abs } \\ \text { Peak \# } & \text { Time } & \text { UV215 } & \text { UV254 } & \text { TIC }(+) & \text { BPM } & \text { UV215 } & \text { UV254 } & \text { TIC }(+) \\ 1 & 0.879 & 100.0 & 100.0 & 100.0 & 592.3 & 3926.63 & 794.55 & 6977298.00\end{array}$
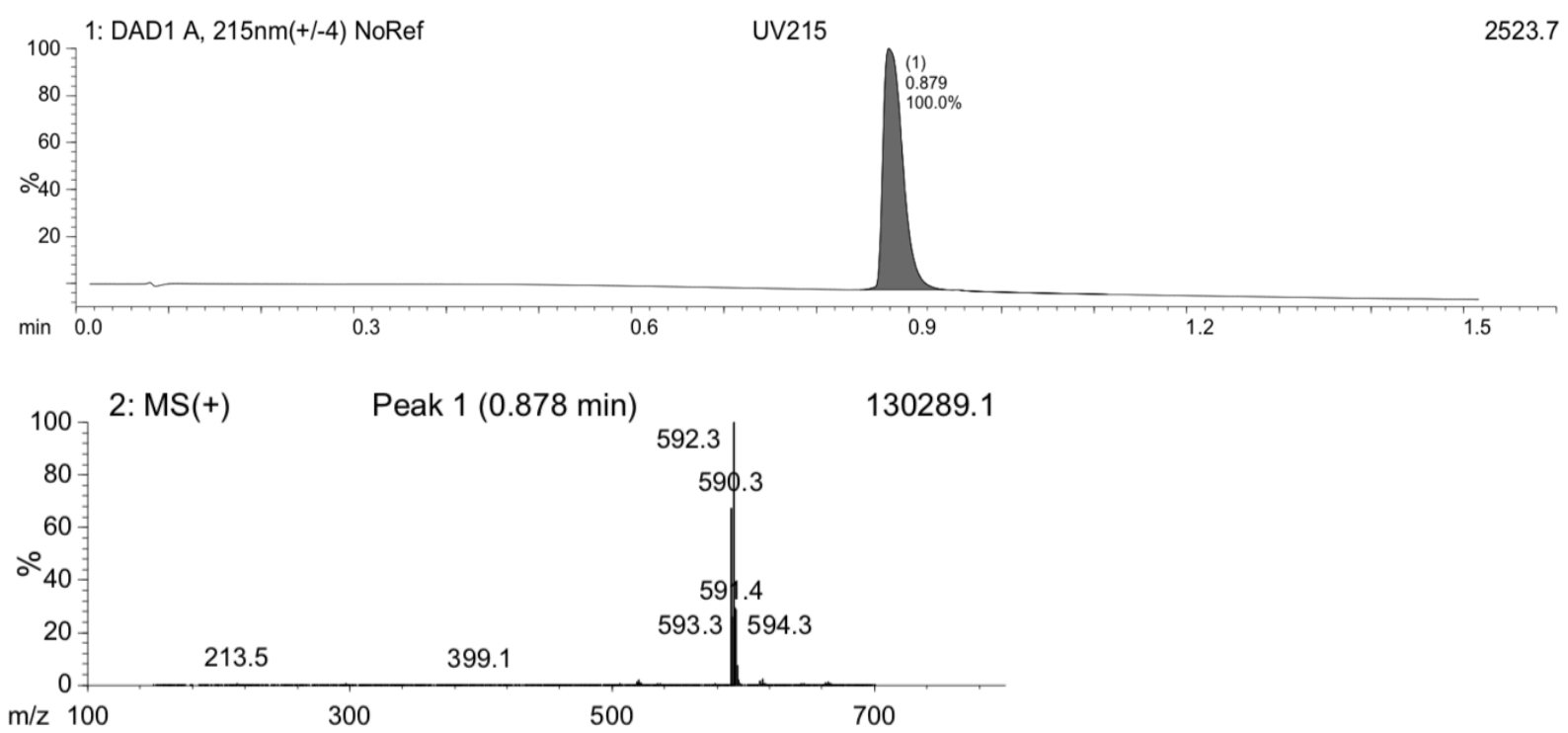
$\underline{\text { HPLC trace of compound } \mathbf{1 1}}$
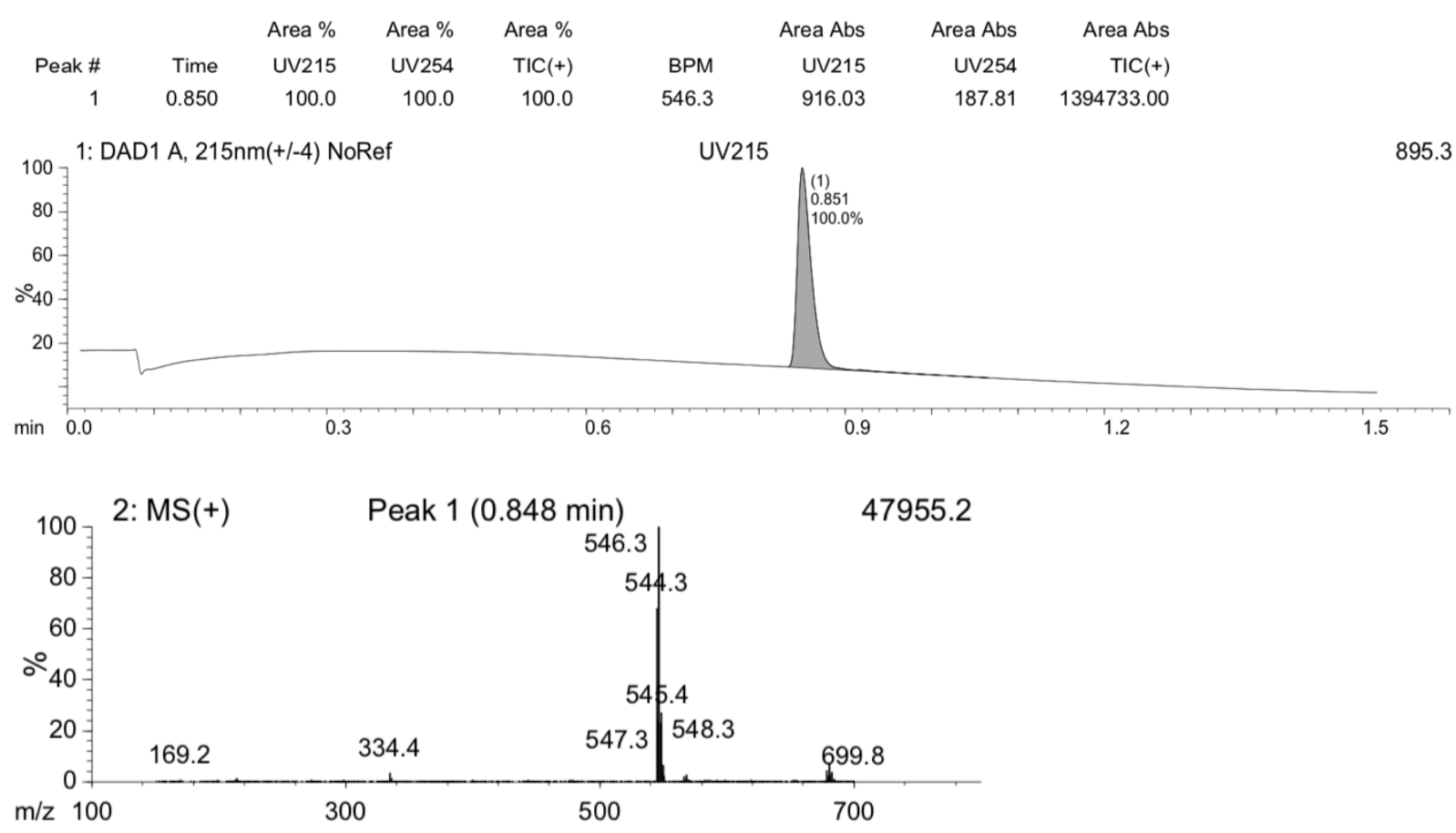

$\underline{\text { HPLC trace of compound } \mathbf{1 2}}$

$\begin{array}{rrrrrrrrr} & & \text { Area \% } & \text { Area \% } & \text { Area \% } & & \text { Area Abs } & \text { Area Abs } & \text { Area Abs } \\ \text { Peak \# } & \text { Time } & \text { UV215 } & \text { UV254 } & \text { TIC }(+) & \text { BPM } & \text { UV215 } & \text { UV254 } & \text { TIC }(+) \\ 1 & 1.039 & 100.0 & 1.0 & 0.0 & 394.4 & 3686.21 & 12.30 & 0 \\ 2 & 1.054 & 0.0 & 99.0 & 100.0 & 500.1 & 0 & 1174.42 & 4443204.50\end{array}$
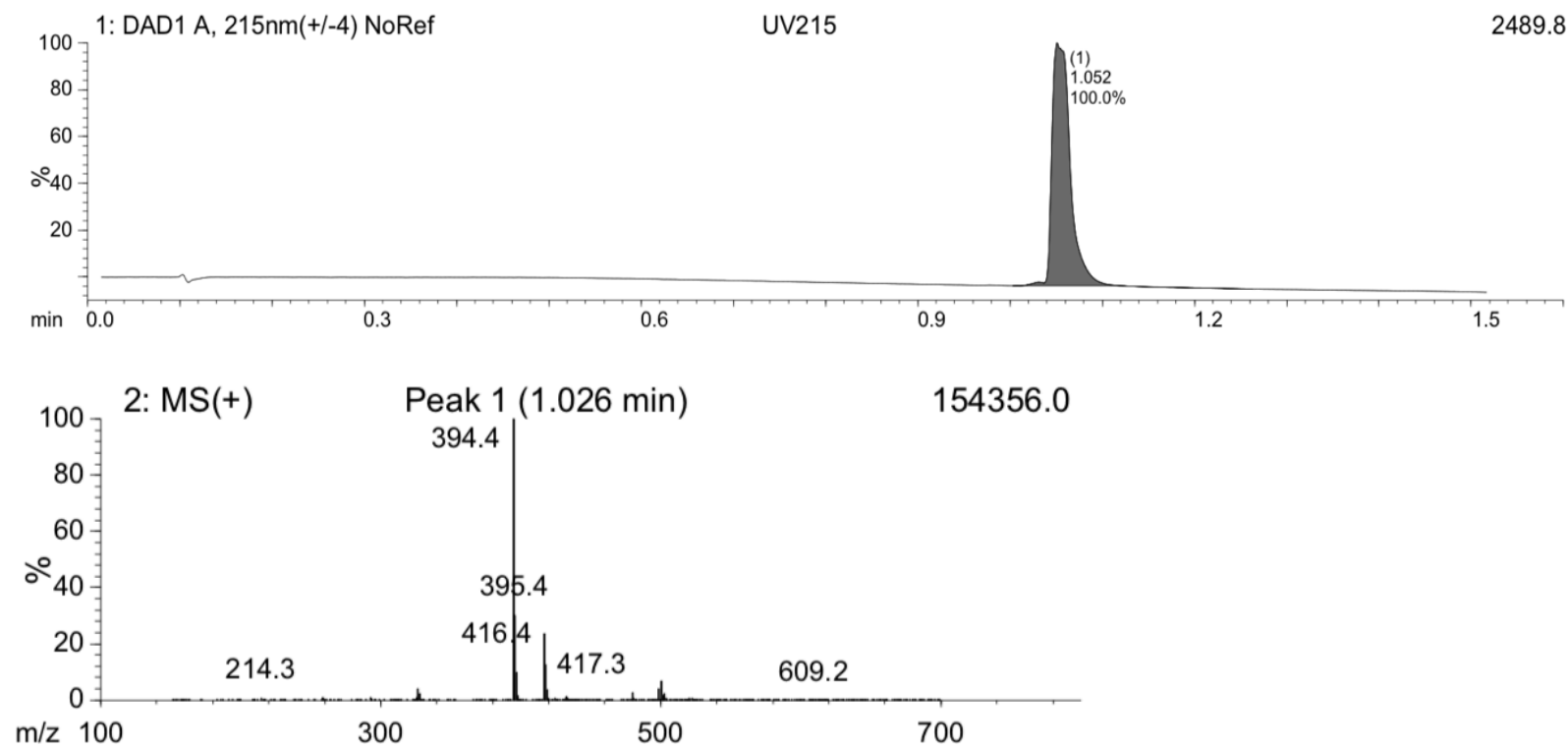